\title{
Concentration, stagnation and inequality: An agent-based approach
}

\author{
Roberta Terranova ${ }^{\mathrm{a}, *}$, Enrico M. Turco ${ }^{\mathrm{b}}$ \\ a BiGSEM, Universität Bielefeld, Universitätsstraße 25, 33615 Bielefeld, Germany, and School of Economics, University of Surrey, 388 Stag \\ Hill, University Campus, Guildford GU2 7XH, UK \\ ${ }^{\mathrm{b}}$ CeNDEF, University of Amsterdam, Roetersstraat 111018 WB, Amsterdam, The Netherlands, and CLE, Department of Economics and \\ Finance, Università Cattolica del Sacro Cuore, Largo A. Gemelli 1, Milan 20123, Italy
}

\section{A R T I C L E I N F O}

\section{Article history:}

Received 3 May 2021

Revised 27 October 2021

Accepted 1 November 2021

Available online 20 December 2021

\section{JEL classification:}

C63

D33

E24

03

04

\section{Keywords:}

Agent-Based models

Technical change

Concentration

Stagnation

Inequality

\begin{abstract}
A B S T R A C T
This paper presents a macroeconomic agent based model with endogenous innovationdriven growth and knowledge accumulation which aims to analyze the underlying causes of the recent increase in market concentration, by focusing on the interplay of technical change and market power, and the resulting macroeconomic consequences in terms of higher inequality and lower growth. The source of concentration lies in the fact that heterogeneous firms do not have equal access to capital-embodied innovations, as we assume that this depends on the "knowledge gap", i.e., the difference between the degree of capital good's technical advancement and the firm's accumulated technological knowledge. The analysis shows that, in the absence of consistent knowledge spillovers and as long as capital goods remain considerably different from each other, technical progress generates systematic differences in productivity across firms, leading to a reallocation of market shares towards more productive firms. Consequently, as the newly-emerging large firms seek to translate the enhanced market power into higher mark-ups, the resulting shift in the income distribution from wages to profits eventually undermines aggregate demand and growth. Yet, simulation experiments reveal that the evolution of market concentration over time as well as its macroeconomic effects crucially depend on the presence (or lack thereof) of legal entry barriers, which, by influencing the process of diffusion of technological innovations, reinforce (or attenuate) the large firms' ability to consolidate their dominant position and thus exploit their market power.
\end{abstract}

(c) 2021 The Author(s). Published by Elsevier B.V. This is an open access article under the CC BY license (http://creativecommons.org/licenses/by/4.0/)

\section{Introduction}

Over the last three decades, advanced economies, particularly the U.S., have undergone major structural changes which manifest themselves in a number of secular trends, i.e., rising market concentration, widening income inequality and secular stagnation (Syverson, 2019).

\footnotetext{
* Corresponding author.

E-mail addresses: roberta.terranova@eiee.org (R. Terranova), enricomariaturco@gmail.com (E.M. Turco).
} 
Since the early 1990s, more than $75 \%$ of U.S. industries have witnessed rising concentration levels, as measured by the Herfindahl-Hirschman (HH) index, which grew on average by 90\% (Grullon et al., 2019). Moreover, many studies have documented a widespread increase in income inequality, especially among western countries, both in the functional and personal distribution (Stiglitz, 2012; Piketty, 2014; Karabarbounis and Neiman, 2014; Atkinson, 2015). In the U.S., excluding the top 1\%, the income share going to wages has plummeted from 75\% in 1980 to $60 \%$ in 2010 (Giovannoni, 2014); real wages have slowed down since the early 1970s, so has productivity but at lower rates, causing the labor share to decline (Benmelech et al., 2018; Barkai, 2020; Autor et al., 2020). More recently, empirical research has made attempts to identify potential links between changes in market structure and income distribution. Barkai (2020), for instance, highlights that firms operating in more concentrated industries have experienced extraordinary high profit rates. This evidence opened a debate, mostly empirical, on the causes and consequences of market concentration. Whilst Autor et al. (2017, 2020) emphasize the role of technical change and productivity gains in enabling superstar firms to achieve a larger market share with less labor, Grullon et al. (2019) and De Loecker et al. (2020) suggest that the rise in corporate profits is mainly driven by increasing profit margins due to market power and entry barriers rather than improvements in operating efficiency. De Loecker et al. (2020), in particular, find that in the U.S. economy mark-ups remained roughly constant between 19501980 and, from then on, have grown steadily, with the average price going from $21 \%$ to $61 \%$ above marginal cost. Against this background, some authors have pointed out that, despite historically low interest rates, increasing profitability and high funds availability, the investment rate of U.S. non-financial corporations has been constantly slowing down from $32 \%$ in the 1980s to 26\% in the 2010s (Gutiérrez and Philippon, 2016; 2017). This evidence is commonly referred to as "investment-profit puzzle", (Stockhammer, 2005; Orhangazi, 2019), paving the way for the rise of corporate sector as net lender (Villani, 2021). Furthermore, according to Gutiérrez and Philippon (2017), such an investment gap is stronger in concentrating industries, where, in view of diminishing profitable investment outlets, monopolistic rents are largely distributed to shareholders by means of dividend payments and share buybacks (Gutiérrez and Philippon, 2016; 2017; Turco, 2018). The slowdown of capital accumulation is then reflected in the long-lasting decline in average output growth, which decreased from $3.7 \%$ between 1947-1980 to $2.7 \%$ between $1980-2017$ (Stiglitz, 2019).

Although the empirical research has lately endeavoured to document and emphasize the potential connections among these trends (Syverson, 2019), in our view, a comprehensive theoretical framework is yet to be developed.

The present paper aims to contribute to filling this gap, by proposing a theoretical framework that allows to systematically analyze the endogenous formation and dynamic interdependence between changes in market structure, income distribution and economic growth. In particular, the goal of this paper is threefold: (i) to develop a macroeconomic agent-based model $(A B M)$ in order to examine the causes and consequences of rising market concentration, by focusing on the interplay of technical change and market power; (ii) to explore, by means of computer simulations, the conditions under which the tendency to concentration at the micro level may give rise to a tendency to stagnation at the macro level; (iii) to implement a variety of policy experiments in order to assess the role of different institutional setups, e.g. entry barriers, and identify the best policy mix able to curb the stagnation tendency and to foster a competitive and innovation-led growth process.

\subsection{Theoretical roots}

To explain the endogenous formation and the dynamic interdependence among the secular trends characterizing modern advanced economies, that is, concentration, stagnation and inequality (Stiglitz, 2019; Syverson, 2019; De Loecker et al., 2020), we propose a narrative that combines old and new findings from the micro- and macro-economic literature on oligopoly, technical change, distribution and growth, and, additionally, introduces some novel features.

First of all, we resume and revise Sylos Labini (1967) theory of oligopoly and technical progress, according to which the tendency to concentration is driven by technical change that generates "technological discontinuities", i.e., systematic differences in productivity across firms, leading to a reallocation of market shares towards more productive firms. This is because heterogeneous firms do not have equal access to capital-embodied innovations, as we assume that this depends on the "knowledge gap", i.e., the difference between the degree of capital vintage's technical advancement and firm's level of technological knowledge. Based on Cohen and Levinthal (1989), we explicitly formalize a process of knowledge accumulation, whose function is to improve firms' ability to identify, assimilate and master the best machines developed by capital good producers. By influencing the firms' access to capital-embodied innovations, the knowledge stock, accumulated over time through R\&D, constitutes a form of technical barrier to entry, or rather to use (Dosi and Nelson, 2010), which underlies the growing divergence in productivity and competitiveness across firms. It follows that, in the absence of consistent knowledge spillovers and as long as capital goods remain considerably different from each other, the intertwined dynamics of knowledge accumulation and technical change is the driver of the endogenous formation of firms' heterogeneity and technical entry barriers, paving the way for a shift in the market structure from a competitive to an oligopolistic form.

The theoretical link between the microeconomic analysis of oligopoly and technical progress and the macroeconomic analysis of income distribution and growth passes through the changing pricing behavior by the large newly-emerging firms.

In a competitive economy, because of low entry barriers and limited market power, firms act as price taker units, i.e., the price converges to unitary cost. In such a context, the falling unit labor cost stemming from technical change translates into lower output prices and subsequently higher real incomes, providing the basis for a self-sustained growth process. At this stage, a rise in concentration due to, e.g., an increased market competition may in fact imply a higher productivity growth and better economic performance, as argued by Autor et al. (2020). 
However, the shift towards an oligopolistic market form following the emergence of technical entry barriers implies that large firms end up with a considerable degree of market power, thus becoming price makers. In the absence of a competitive pressure, the price is not taken as given, but is set endogenously by firms, which apply a mark-up over unit labor cost according to their 'degree of monopoly power', as reflected in the individual market share (Kalecki, 1942). Operating under conditions of oligopoly characterized by technical entry barriers, large firms seek to translate the enhanced market power into higher profit margins. Consequently, as the influence of large firms grows over the economy, the rise in the weightedaverage mark-up leads to a shift in the income distribution from wages to profits that eventually undermines consumption and aggregate demand (Keynes, 1936), with detrimental effects on investment and long-run growth. As a result, in the absence of countervailing forces, the tendency to concentration at the micro level may give rise to a tendency to stagnation at the macro level. ${ }^{1}$

\subsection{The formal model: key features and properties}

We formalize this framework and further explore its dynamic properties by means of an agent-based macroeconomic model. From a methodological point of view, we believe that an ABM is the most appropriate tool to address our research question. Indeed, we exploit the granularity of the agent-based approach to study the endogenous evolution of firms' heterogeneity underlying the emergent dynamics of concentration, without resorting to different initial conditions across firms or exogenous shocks to the parameters of the model. By contrast, similar studies based on a standard (partial) equilibrium framework, such as Autor et al. (2020), require firms to be initially endowed with different productivity levels, while the rise in concentration occurs through an exogenous change that allocates more market share to more productive firms, e.g. through an increase in the consumers sensitivity to prices. In our framework, such a reallocation mechanism is endogenous to the model dynamics and results from the firms choice of heterogeneous capital vintages in a decentralized capital goods market. This allows us not only to describe the effects of rising concentration on the economic system but also to explain the forces behind this process.

In line with the macro-evolutionary tradition, our model is characterized by endogenous technical change and heterogeneous capital goods, whose built-in productivity depends on a stochastic innovation process. Yet, differently from many ABMs in this literature where the innovation activity is carried out exclusively by capital good firms (K-firms hereafter) to search for new innovations and to imitate that of competitors (Dosi et al., 2010a; Dawid et al., 2019; Caiani et al., 2018), in our model also consumption good firms (C-firms) can invest in R\&D in order to accumulate technological knowledge, which allows them to identify and employ the best techniques produced by K-firms. Following the seminal work of Cohen and Levinthal (1989), technological knowledge can either be generated internally by means of firms' own R\&D or externally by absorbing knowledge spillovers coming from other firms. The knowledge stock, in turn, affects the firms' choice of capital vintages, which depends on the "knowledge gap", i.e., the difference between the degree of capital good's technical advancement and firm's accumulated technological knowledge. Therefore, throughout the process of capital accumulation, firms with greater technological knowledge are more likely to adopt more efficient machines, thus achieving faster productivity gains.

The remaining part of the model incorporates the following features: the households sector consists of workers and firm owners, who earn labor and capital income, respectively, and consume a homogeneous good produced by C-firms using labor and heterogeneous capital; a single representative bank collects deposits from households and firms, extends credit to borrowing firms and buys Government bonds; the Government levies taxes on wages and dividends and distributes unemployment subsidies to non-working individuals. Despite starting with the same initial conditions, households and firms become heterogeneous over time by virtue of the casual interactions in decentralized labor, consumption and capital good markets.

The model is able to reproduce the intertwined stylized facts of concentration, stagnation and inequality. These dynamics emerges 'from the bottom up', as a result of the adaptive behavior of heterogeneous agents interacting in decentralized markets. In particular, after a short period of transition, the model endogenously generates a wave of market concentration driven by technical change, which leads to a reallocation of market shares towards more productive and knowledge-intensive firms. Consequently, large firms tend to exert their enhanced market power to raise mark-ups. The ensuing slowdown in real wages determines a shortage in aggregate demand, on the one hand, and excess capacity, on the other. As a result, firms cope with the lower demand by reducing the utilization rate of the existing plants without investing in new capital formation, net of depreciation, with negative effects on output and productivity growth. Therefore, the economic system spontaneously reaches a state of stagnation owing to changes in market structure and income distribution, triggered by technical progress and market power.

However, by comparing two alternative scenarios corresponding to different patent system regulations, we find that, when K-firms are allowed to imitate their competitors' technologies, market competition is soon re-established. This is because the imitation activity carried out by K-firms brings about a convergence amongst different techniques, which, by reducing technological discontinuities in the consumption sector, allows laggards to catch up. Conversely, in the "no-imitation" scenario, the persistent heterogeneity among capital goods is then reflected in the systematic divergence in productivity across C-firms. In such a scenario, in so far as legal entry barriers reinforce technological discontinuities, large firms are able

\footnotetext{
${ }^{1}$ Baran and Sweezy (1966), Sylos Labini (1967) and Steindl (1976) previously reached similar conclusions, albeit from different perspectives.
} 
to consolidate their dominant position and to extract a higher share of rents, with harmful effects on demand and growth also in the long run.

Therefore, from our simulation analysis it emerges that, whereas the initial wave of concentration is triggered by knowledge-based technical entry barriers, which constrain firms' access to capital-embodied innovations, the evolution of concentration over time as well as its macroeconomic effects crucially depends on the presence (or lack thereof) of legal entry barriers, which, by influencing the process of diffusion of technological innovations, reinforce (or attenuate) the large firms' ability to exploit their market power.

Our simulation results are in line with Nelson and Winter (1978) analysis of the forces generating and limiting concentration under Schumpeterian competition. One of their main findings is that the evolution of industry concentration is significantly affected by the effectiveness of technological imitation efforts. Moreover, in so far as firms undertake investment decisions in response to changes in perceived market power, they find that large firms operating in concentrated industry have less incentives to invest if they expect a sufficiently high mark-up. In both respects, our analysis can be seen as complementary to the industry-level model developed by Nelson and Winter (1978), as we investigate in a macroeconomic framework not only the role of entry barriers on industry concentration and market power, but also the resulting macroeconomic consequences in terms of high inequality and low growth. More generally, our findings suggest that the pattern of economic growth is driven by the dynamic interrelationship between technological evolution in the capital sector and market power in the consumption sector, with following non-trivial effects on income distribution and aggregate demand.

Finally, drawing on the ongoing debate on the macroeconomic consequences of concentration, we address the question: "can concentration be good for the economy?". We answer this question by means of a sensitivity analysis in order to assess the impact of a higher degree of competition on HH index and GDP. We find that, in the baseline scenario with imitation, a competition-driven concentration may actually benefit growth, while this is no longer true in the presence of legal entry barriers fostering market power. These findings suggest that it is the degree of persistence, more than its level per se, that determines whether or not market concentration benefits the economy. A high and volatile concentration may foster growth as long as competitive forces bring about a continuous reallocation of market shares towards more productive firms, without them having the opportunity to consolidate and exploit a dominant position. Conversely, a persistent market concentration triggered by the presence of legal barriers enables large firms to exert the enhanced market power to extract higher rents, with negative effects on income distribution and economic growth.

\subsection{Existing literature}

The present work provides a contribution to four streams of literature.

First of all, this paper belongs to the increasing body of literature on macroeconomic agent-based models, of which Dawid and Delli Gatti (2018) provide an extensive review. In particular, our model builds upon Assenza et al. (2015), who develop a macro ABM with capital and credit in order to investigate how the interaction between firms of different sectors and the evolution of their financial conditions lead to the emergence of recurrent economic crises. Moreover, we incorporate features from macro-evolutionary ABMs (e.g., see Deissenberg et al., 2008; Dosi et al., 2010a; Caiani et al., 2019; Dawid et al., 2019), where technical progress is driven by stochastic innovations introduced in the economy by firms producing new capital goods. Macroeconomic agent-based models have been employed to study various complex economic phenomena as well as to address a wide range of policy questions (Fagiolo and Roventini, 2017; Dosi and Roventini, 2019). Narrowing the focus on the issues discussed in this paper, while there are numerous studies on inequality (e.g. Dosi et al., 2013; Russo et al., 2016; Dawid et al., 2018; Dosi et al., 2018; Cardaci, 2018; Caiani et al., 2019) and, to a lesser extent, on large-scale economic downturn (e.g. Giri et al., 2019), the causes and consequences of rising market concentration, especially in relation with income inequality and economic stagnation, are less investigated in the macro ABM literature. Similar attempts include Hepp (2021), who, building on the EURACE model (Dawid et al., 2019), studies the impact of technical change on industry concentration and firm dynamics, and Dawid et al. (2021), who applies the EURACE model to examine the role of different degrees of centralization of the wage setting process on concentration and inequality. While these papers are close in spirit to ours, their analyses do not focus on the 'dark side' of industry concentration in terms of market power and rent extraction. By contrast, our model allows to highlight the twofold nature of innovation, which boosts growth but also market power.

Secondly, this paper contributes to the ongoing debate on the causes and consequences of market concentration. In the current, mostly empirical literature it is possible to identify two alternative views that we will label as "efficiency-enhancing" and "rent-extracting" concentration hypotheses. According to the efficiency-enhancing hypothesis, market concentration is the outcome of technical change spurred by the adoption of more efficient techniques by large ("superstar") firms (Autor et al., 2020). By exploiting scale economies and low unitary costs, those firms are able to sustain big upfront innovative investment, hence achieving productivity gains, cost reductions and larger market shares. Therefore, rising concentration, by improving the efficient allocation of resources and fostering aggregate productivity, has a positive impact on the economy, although it may come at the cost of a lower wage share following the introduction of labor-saving innovations (Autor et al., 2017).

On the other hand, according to the rent-extracting hypothesis, market concentration is associated with the enhanced market power resulting from higher entry barriers, either legal or technological, which undermine competition by preventing potential rivals from entering the market (Grullon et al., 2019; Barkai, 2020; De Loecker et al., 2020). The enhanced market 
power is then reflected in higher mark-ups, leading to a shift in the income distribution from wages to profits. From a macroeconomic perspective, a falling labor share determines a decline in aggregate consumption because "those at the top have lower propensity to consume than those at the bottom" (Stiglitz, 2019). Moreover, due to the lack of competitive threats, firms operating in concentrated industries might have less incentives to innovate, while patent protections may restrict laggards' possibility to imitate, with this resulting in lower investment (Decker et al., 2016; Gutiérrez and Philippon, 2019). As a result, the process of market concentration, by exacerbating income inequality and weakening aggregate demand, is detrimental to economic growth.

In their analysis of intangible capital and concentration, Crouzet and Eberly (2019) put forward a third interpretation, based on the idea that the two aforementioned hypotheses, rather than mutually exclusive, can be regarded as two alternative equally-likely scenarios that arise depending on the sources of rising concentration. In this view, concentration might be "good", if triggered by productivity-enhancing technological innovations, or "bad", if due to entry barriers giving rise to market power. ${ }^{2}$ Using U.S. firm and industry level data between 1988-2015, the authors find mixed, sector-specific evidence on the impact of rising concentration on business investment and economic performance, claiming that this would provide support to their thesis.

Like Crouzet and Eberly (2019), we are reluctant to consider the two above mentioned hypotheses as mutually exclusive. However, by adopting a complex approach, we believe it is possible to develop an analytical framework wherein the effects of concentration are not necessarily pre-determined by its sources, but they result from the dynamic interaction between technical change and market power, and their relationship with the changing institutional environment. In other words, it may happen that a rising market concentration, even if triggered by technical change, eventually result in rent-extracting activities due to the emergence of technological entry barriers.

Thirdly, the present paper faces the challenge of incorporating features from the empirical and theoretical literature specialized on innovation and knowledge accumulation into a comprehensive macroeconomic model. As Aistleitner et al. (2020) point out, in fact, despite the literature clearly shows that the process of acquisition and diffusion of new technological capabilities is an important determinant for growth and development on the national and regional level (Acemoglu and Zilibotti, 2001), as well as for the business success on the firm level (Cohen and Levinthal, 1990), in the macroeconomic modelling framework little attention is given to the precise mechanisms according to which such a capability accumulation takes place. More specifically, by the way in which we formalize the firm's choice of capital vintages, this paper creates a bridge between the macro and the micro/industrial evolutionary literature of innovation and technical change. In the macro-evolutionary framework (Dosi et al., 2010a), the corporate sector is typically composed of consumption good firms and capital good firms whereby the former buy machine tools produced by the latter based on their economic efficiency, i.e., the sum of price and unit labor cost resulting from the adoption of the observed machineries. This means that, once taking into account the transaction costs, all consumption firms have same access to technological innovations and, for a given price, will choose the most advanced ones, i.e., the machineries implying the lowest unit labor cost, without facing any technical constraints. On the other hand, numerous studies in the micro-evolutionary literature stress the role of technological knowledge and capability accumulation in the success of innovative activities carried out by (capital good) firms (Cantner and Pyka, 1998; Cohen and Levinthal, 1989; Dawid, 2006). This paper proposes a synthesis of the two approaches by conceiving technological knowledge as a means to improve the C-firms' ability to employ the best machines produced by K-firms. As such, the knowledge stock has a similar function as the average skill level of workers in the EURACE model (Dawid et al., 2019), where the firm's choice of a capital vintage depends upon the expected future effective productivity, which, in turn, may be possibly constrained by the workers' accumulated capabilities. In this regard, the main difference with the EURACE model is that while in Dawid et al. (2019) technological knowledge is embedded in the skill level of workers, we put forward an explicit formalization of the process of knowledge accumulation, which evolves over time by means of firm's own R\&D investment as well as knowledge spillovers coming from other firms, in tune with Cohen and Levinthal (1989). This view is empirically supported by Dosi et al. (2019), who, exploring an Italian micro-level data set in the period 2010-2014, find a weak relationship between workers training activities and labor productivity, suggesting that the organizational structure is the locus of knowledge rather than individuals.

Admittedly, the characterization of firms technical knowledge provided in the paper overlooks some important insights of evolutionary theory on the complex nature of technical knowledge and innovation. In particular, innovation is not only associated with productivity gains, but it contributes to affect and, in turn, is affected by the direction of technical change (cfr., Dosi, 1982; Caiani, 2017). As proposed by Dosi (1982), within a technological paradigm there are multiple potential technological trajectories on which firms can specialize, each involving the development or the absorption of specific pieces of technical knowledge. According to this view, the technological innovations a firm has access to do not only depend on the firms level of technical knowledge, but also on the coherence between the type of technical knowledge involved in the capital goods and the technical trajectories on which firms have been specializing on. However, as Nelson and Winter (1982) point out, once a given technological path has been selected and established, there emerge ǣnatural trajectories toward mechanisation and exploitation of economies of scaleg, whereby the direction of technical change might be less unpredictable. Building on these insights, the implicit assumption of our model is that technical progress unfolds along a well

\footnotetext{
2 "The source of rising concentration is thus important for understanding the extent to which rising concentration is efficient or not, and possible policy implications." (Crouzet and Eberly, 2019).
} 
established technological trajectory. This, in our view, allows for a stylized characterization of technical knowledge, similar to that proposed by Dawid et al. (2019).

Finally, the present paper relates to the evolutionary literature investigating the relationship between technological regimes and Schumpeterian patterns of innovation. According to Nelson and Winter (1982), a technological regime is defined as the particular combination of factors such as technological opportunities, appropriability of innovations, cumulativeness of technological advances and properties of the knowledge base characterizing a class of technological innovations. It has been shown that these technology-related factors greatly affect the process of innovation and competition of an industry, causing the emergence of either a 'Schumpeter Mark I' or 'Schumpeter Mark II' innovation patterns (Malerba and Orsenigo, 1996). The former is characterized by high opportunity and low appropriability conditions, which favor the frequent entry of new innovative firms. The latter, instead, is dominated by large incumbent firms which are able to exploit high opportunity and appropriability conditions, allowing innovators to continuously accumulate technological knowledge and build up innovative advantages over non-entrants. In this paper, special attention is devoted to the role of appropriability conditions, here intended as the ability to protect innovations from imitation by means of legal and technological barriers. Indeed, our simulation results show that, when imitation is allowed (low appropriability), the economy is characterized by competitive and dynamic markets populated by a great number of small innovative firms, coherent with 'Schumpeter Mark I'. Conversely, the presence of legal barriers to imitation (high appropriability) is associated with higher and more persistent concentration levels driven by the emergence of big knowledge-intensive firms, in tune with a 'Schumpeter Mark II'.

\section{Model setup}

The model is characterized by (i) a corporate sector, including $N$ capital good producers (or innovators) and $F$ consumption good producers (or entrepreneurs); (ii) a household sector, composed of $W$ workers and $K=N+F$ capitalists, i.e., one owner per firm; (iii) a banking sector with one representative bank; (iv) a public sector, namely the Government.

The structure of the model builds upon the macro agent-based model with capital and credit (CC-MABM) developed by Assenza et al. (2015). A few major changes are introduced with respect to the parental model: (i) C-firms' quantity and price decisions are taken separately, being the former based on expected sales, while the latter on the degree of market power; (ii) capital goods are heterogeneous with respect to built-in productivity, whose improvements depend upon a stochastic innovation process la Dosi et al. (2010a); (iii) C-firms also perform R\&D in order to accumulate technological knowledge, which enhances their ability to identify and employ the best machines produced by innovators.

Coherent with Assenza et al. (2015), workers and firms are heterogeneous agents and interact in decentralized labor, consumption and capital goods markets. In the labor and consumption good markets, the interaction occurs via the searchand-matching mechanism (Riccetti et al., 2015), while the choice of the capital vintage is determined by a logit model, similarly to Dawid et al. (2019).

The reason why we adopt different matching protocols for different markets is essentially twofold. The first reason relates to the peculiar features of each market. In particular, the size of capital goods market is significantly smaller compared to the others: the ratio between supply-demand units is $5 \%$ against $9 \%$ and $10.5 \%$ in the consumer and labor markets respectively. As such, in the labor and goods markets, demand-agents can only visit a subset of supply-agents, following a search-and-matching mechanism, while, C-firms can potentially visit all the suppliers in the market for capital goods. However, the presence of bounded rationality makes the selection of capital vintage not entirely deterministic, as captured by the logit model. The second reason is that, by assuming that firms have potentially access to the same set of machineries, the probability of choosing a given vintage crucially depends on the firms' ability to exploit the capital-embodied innovations, which in turn depends on the knowledge gap. Therefore, the logit model allows us to emphasize and investigate more in depth the role of firms accumulated knowledge in the process of acquisition of heterogeneous capital goods which underlies the endogenous emergence of market concentration.

\subsection{Sequence of events}

Over one period of the simulation run, events unfold in the following order:

1. Production planning and factors demand: Based on expected sales, C-firms compute desired production, utilization rate and labor demand for both production and research workers.

2. Capital goods market (1): C-firms select their potential supplier of machine tools based on the price and effective productivity, which in turn depends on the 'knowledge gap', i.e., the difference between capital goods' technical advancement and C-firms' level of technological knowledge.

3. Credit market: If planned production costs exceed internal funds, C-firms resort to the bank asking for a loan.

4. Labor market: Firms can hire and fire production and research workers according to their labor requirements; employees receive a wage, net of taxes.

5. Production and price: C-firms' production is computed as the minimum between desired and potential output, given the available resources; the price is set by charging a mark-up over the unit labor cost depending on the firm's degree of market power. 
6. Capital goods market (2): Entrepreneurs with a positive investment demand buy the required capital units from the previously selected supplier. Capital goods, produced by innovators according to a Make-to-Order plan, are made available for the production process starting from next period.

7. RED activity (1): Both consumption and capital good firms carry out R\&D activity based on previously allocated funds: C-firms update their knowledge stock; K-firms perform innovation and imitation activities to develop more efficient vintages of capital goods.

8. Taxes and subsidies: Government collects taxes on wages and dividends and distributes unemployment benefits to non-working individuals.

9. Consumption goods market: Having defined their consumption budget, households visit a given number of firms and choose the supplier after comparing their selling prices.

10. Profits and dividends: Firms collect revenues and distribute part of their profits to capitalists as dividends, on which the Government collects taxes.

11. RED activity (2): Both consumption and capital good firms allocate part of realized profits to the R\&D budget that will be invested in the following period.

12. Entry-exit dynamics: Retained earnings accumulate to net worth. If the equity turns negative or liquidity is not enough to repay interests and debt installments, firms declare default. Bankrupted firms are re-capitalized by means of the owner's wealth.

13. Public deficit and bond issuance: The Government issues bonds, purchased by the bank, to finance the public expenditure in excess of tax revenues; public debt is updated accordingly.

14. Bank's profits, dividends and equity: The bank collects interest payments from borrowings, records non-performing loans and distributes dividends to capitalists; after-dividends earnings pile up to the bank's equity. If the latter turns negative, all households participate to the bail-in proportionally to the scale of their deposits.

\subsection{Corporate sector}

\subsubsection{Consumption good firms}

Quantity choice C-firms produce a homogeneous consumption good using labor and heterogeneous capital goods. Being unable to observe actual demand, the desired output, $\tilde{Y}_{i t}$, is set on the basis of expected sales, $S_{i t}^{e}$, as computed by means of a simple adaptive rule depending on past forecasting errors, according to Eq. (2). Additionally, in defining the planned production, firms take into account: (i) the desired inventory level, given by a fraction $\kappa$ of expected sales, in order to hedge against short-term demand swings (Caiani et al., 2020), (ii) the involuntary inventories of unsold goods, inv $v_{i t-1}$, inherited from the past period, which depreciate at a rate $\delta^{i n v}$. Hence, the desired output is defined as

$$
\begin{aligned}
& \tilde{Y}_{i t}=S_{i t}^{e}(1+\kappa)-i n v_{i t-1}, \\
& S_{i t}^{e}=S_{i t-1}^{e}+\rho\left(S_{i t-1}-S_{i t-1}^{e}\right) .
\end{aligned}
$$

Because frictions in the labor or credit markets may possibly constrain firms' factor demands, the actual scale of economic activity is computed as the minimum between desired and potential output. To produce the consumption good, firms combine labor and heterogeneous capital in fixed proportions, according to a Leontief technology, that is

$$
Y_{i t}=\min \left(\sum_{v \in V_{i t}} \omega_{i t}^{v} k_{i t}^{v} \bar{A}_{i t}^{v}, \alpha_{i t} N_{i t}\right),
$$

where $V_{i t}$ is the set of capital goods owned by firm $i$ at time $t, \omega_{i t}^{v}$ is the utilization rate relative to each capital vintage $v$, $k_{i t}^{v}$ and $\bar{A}_{i t}^{v}$ are the amount of capital units of type $v$ and its related effective productivity, respectively, $\alpha_{i t}$ is the current labor productivity, given by the productivity of capital multiplied by the constant capital-labor ratio. As shown in Eq. (9) below, the effective productivity of capital goods depends on the ability of firm $i$ to exploit their built-in technology.

C-firms respond to short run fluctuations in expected sales by adjusting the rate of capacity utilization as well as the required workforce, whereas the capital stock is modified according to long-run production requirements, in tune with Assenza et al. (2015).

Determination of utilization capacity

Having defined the desired level of production, the required utilization rate by capital vintage, $\omega_{i t}^{v}$, and labor demand, $N_{i t}$, are derived from Eq. (3). Following Caiani et al. (2020), in each period C-firms rank the available machine tools based on their built-in productivity $-v=1,2,3, \ldots$ with the first being the most productive - and employ them in the production process starting from those with the highest quality. The desired utilization rate of capital vintage $v$ by firm $i$ is determined according to the following algorithm:

$$
\tilde{\omega}_{i t}^{v}= \begin{cases}1 & \text { if } \sum_{s=1}^{v-1} \tilde{\omega}_{i t}^{s} k_{i t}^{s} \bar{A}_{i}^{s}+k_{i t}^{v} \bar{A}_{i}^{v} \leq \tilde{Y}_{i t} \\ \frac{\tilde{Y}_{i t}-\sum_{s=1}^{v-1} \tilde{\omega}_{i t}^{s} k_{i t}^{s} \bar{A}_{i}^{s}}{k_{i t}^{v} \bar{A}{ }_{i}^{v}} & \text { if } \sum_{s=1}^{v-1} \tilde{\omega}_{i t}^{s} k_{i t}^{s} \bar{A}_{i}^{s} \leq \tilde{Y}_{i t} \text { and } \sum_{s=1}^{v-1} \tilde{\omega}_{i t}^{s} k_{i t}^{s} \bar{A}_{i}^{s}+k_{i t}^{v} \bar{A}_{i}^{v}>\tilde{Y}_{i t} \\ 0 & \text { if } \sum_{s=1}^{v-1} \tilde{\omega}_{i t}^{s} k_{i t}^{s} \bar{A}_{i}^{s} \geq \tilde{Y}_{i t} .\end{cases}
$$


Labor demand C-firms need workers to carry out both production and R\&D activities. To preserve the stock-flow consistency of the model, in fact, the research budget is used to hire workers who perform R\&D activity during the current period. Given the desired rate of utilization, $\tilde{\omega}$, and the constant capital-labor ratio, $\bar{l}_{k}$, labor demand for production is given by

$$
\tilde{N}_{i t}=\sum_{v \in V_{i t}} \tilde{\omega}_{i t}^{v} \frac{k_{i t}^{v}}{\bar{l}_{k}}
$$

If labor demand $\tilde{N}_{i t}$ is greater than the current workforce $N_{i t-1}$, or if R\&D investment is positive ${ }^{3}$, firms post vacancies on the job market, hence defined as

$$
J_{i t}= \begin{cases}\max \left(\tilde{N}_{i t}-N_{i t-1}, 0\right)+\frac{R D_{i t}}{w_{t}} & \text { if } \frac{R D_{i t}}{W_{t}}>1 \\ \max \left(\tilde{N}_{i t}-N_{i t-1}, 0\right) & \text { otherwise }\end{cases}
$$

where $w_{t}$ is the market wage uniform across firms.

The job market unfolds according to the search and matching process (cfr. Assenza et al., 2015): unemployed workers visit $Z_{e}$ randomly sampled firms and get hired at the prevailing wage as they encounter one firm with available job vacancies. This means that firms can fill their open positions only if they are visited by a sufficient number of unemployed workers. It follows that, despite the absence of transaction costs on the labor market, i.e., firms can hire or fire employees at no cost, the presence of firms with job vacancies can coexist with unemployed workers looking for a job. In case the current number of employees exceeds labor requirements, i.e., $\tilde{N}_{i t}<N_{i t-1}$, workers in excess are randomly selected from the firm's workforce and then fired.

$R E D$ and technological knowledge The R\&D budget is determined as a constant fraction of past net profits, i.e., $R D_{i t}=$ $\sigma^{c} \pi_{i t-1}^{\text {net }}$. The purpose of research activity carried out by C-firms is to accumulate a stock of technological knowledge, which, in turn, improves their ability to identify and employ the best machines produced by K-firms. The idea is that technological knowledge is not entirely a public good, but costly to acquire and process; as such, it requires prior R\&D investment (Dosi and Nelson, 2010). Following the seminal work by Cohen and Levinthal (1989), R\&D spending has a dual role in the process of knowledge accumulation: (i) to generate new technical knowledge; (ii) to increase the firm's 'absorptive capacity', i.e., its ability to assimilate external knowledge spillovers. Thus, the knowledge stock, $z_{i t}$, evolves according to

$$
z_{i t}=\left(1-\delta^{z}\right) z_{i t-1}+R D_{i t}+\gamma_{i t}\left(\psi \sum_{j \neq i} R D_{j t}\right)
$$

where

$$
\begin{aligned}
& \gamma_{i t}=1-e^{-\eta \overline{R D}_{i t},} \\
& \overline{R D}_{i t}=\xi \overline{R D}_{i t-1}+(1-\xi) R D_{i t} .
\end{aligned}
$$

According to Eq. (6), the knowledge stock is generated both internally through firm's own R\&D investment and externally by absorbing knowledge spillovers coming from other firms' R\&D activity, with $\psi$ indicating the degree of knowledge spillovers. ${ }^{4}$

The absorptive capacity, $\gamma_{i t} \in(0,1)$, is determined endogenously based on firm's own R\&D experience, where $\overline{R D}_{i t}$ is the weighted average of current and past R\&D spending with exponentially decaying weights. Note that the fact that the absorptive capacity is firm-specific emphasizes the role of firms' heterogeneity in the acquisition process of external knowledge spillovers, regardless of $\psi$.

Choice of capital vintage

C-firms invest in R\&D in order to accumulate technological knowledge, which allows to enhance their ability to identity and employ the best machine tools on the market. The process of knowledge accumulation, therefore, plays a crucial role in the firm's choice of capital goods.

In particular, the effective productivity that firm $i$ can get by employing the capital vintage $v$ is determined by the 'knowledge gap', i.e., the difference between the degree of capital good's technical advancement, $A^{v}$, and the firm's level of technological knowledge, $z_{i}$, both normalized into the range $[0,1] .^{5}$ The function of the effective capital productivity is defined in Eq. (9) and displayed in Fig. 1. It states that firm $i$ can fully exploit the productivity of vintage $v$ as long as the knowledge gap is negative, that is the degree of technological knowledge is greater than or equal to the capital's technical advancement. Otherwise, the knowledge gap acts as a constraint which becomes tighter the greater the size of the

\footnotetext{
${ }^{3}$ The number of research workers hired by the firm is given by the ratio between R\&D spending and nominal wage rounded down to the nearest integer.

${ }^{4}$ A similar formalization of the knowledge accumulation process was firstly proposed by Cohen and Levinthal (1989) to investigate both empirically and theoretically the two faces of R\&D as source of generation and absorption of technical knowledge. The authors test this hypothesis on survey data on technological opportunity and appropriability conditions collected by Levin et al. (1987), and data on business unit R\&D expenditures from the Federal Trade Commission's Line of Business Programme. Compared to the original equation, our version excludes the role of extra-industry spillovers and, in order to adapt it to a dynamic setting, includes a depreciation rate, $\delta^{z}$, which captures obsolescence effects arising in the long run.

${ }^{5}$ The variables are normalized by means of a min-max normalization procedure, i.e., $\hat{x}=\frac{x-\min (x)}{\max (x)-\min (x)}$.
} 


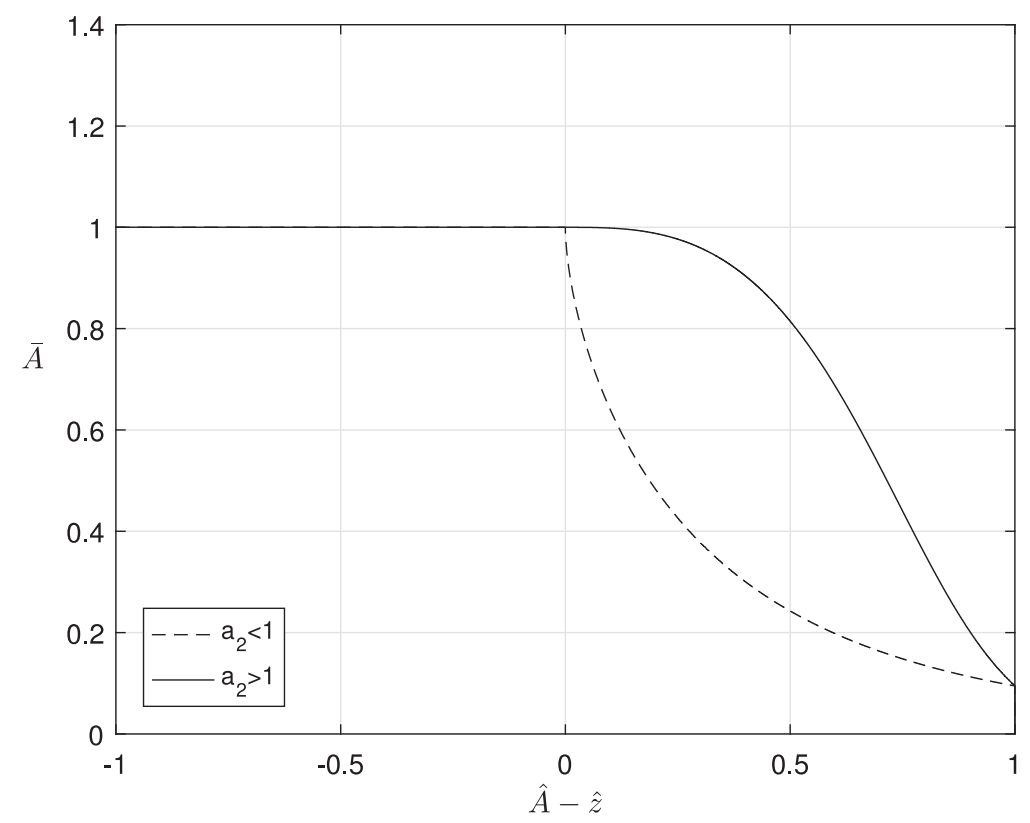

Fig. 1. Effective productivity of capital vintage, $\bar{A}_{i t}^{v}$, as a function of the knowledge gap, $\hat{A}_{i t}^{v}-\hat{Z}_{i t}$. The slope of the function represents the intensity of the knowledge constraints.

knowledge gap.

$$
\bar{A}_{i t}^{v}= \begin{cases}A_{t}^{v} & \text { if } \hat{A}_{t}^{v} \leq \hat{z}_{i t}, \\ \frac{2 A_{t}^{v}}{1+e^{a_{1}\left(\hat{A}_{t}^{v}-\hat{z}_{i t}\right)^{a_{2}}}} & \text { otherwise, }\end{cases}
$$

with $a_{1}, a_{2}>1 .^{6}$

Having computed the effective productivity for each vintage of capital, the firms' choice of capital goods is determined through a logit model (Dawid et al., 2019). The decision is random, where the probability for firm $i$ of selecting a machine $v$ depends positively on its effective productivity, $\bar{A}_{i t}^{v}$, and negatively on its price, $p_{t}^{v}$, that is,

$$
\mathbb{P}[\text { Firm } i \text { selects vintage } v]=\frac{\exp \left[\beta \log \left(\frac{\hat{A}_{i t}^{v}}{p_{t}^{v}}\right)\right]}{\sum_{v=1}^{V} \exp \left[\beta \log \left(\frac{\hat{A}_{i t}^{v}}{p_{t}^{v}}\right)\right]},
$$

where $\beta \in(0, \infty)$ is a parameter governing the intensity of choice, i.e., how fast firms choose a vintage $v$ coherent with their technological knowledge.

Equations (9) and (10) state that, for a given price, the probability for firm $i$ of selecting a given capital vintage $v$ is increasing with its effective probability, which, in turn, is inversely proportional to the knowledge gap with respect to that particular technology. In other words, firms with greater accumulated knowledge are more likely to choose the most advanced capital goods.

The underlying motivation is that to access and master the most efficient machines produced by innovators, C-firms require to build up an in-house technical capacity. In this sense, the technological knowledge shall be considered as the firm's know-how, that is the set of skills and abilities accumulated over time by means of R\&D. As such, it constitutes a form of technological barrier to entry, or rather to use (Dosi and Nelson, 2010), which, by influencing firms' access to technological innovations, is the ultimate driver of firms' heterogeneity and productivity differentials.

Investment demand Since capital is a fixed input in the short run - i.e., investment goods acquired in $t$ can be employed in the production process starting from $t+1-$, C-firms ignore temporary fluctuations in observed demand and undertake investment decisions in order to achieve a desired level of production capacity. The latter is obtained by discounting the long-run desired production for the target utilization rate, $\frac{\bar{Y}_{i t-1}}{\bar{\omega}}$, where $\bar{Y}_{i t-1}$ is simply a weighted average of past desired production defined in Eq. (1).

\footnotetext{
${ }^{6}$ There are a number of works that document the importance of complementarities between firms technical know-how and their ability to employ the new technological innovations (Bresnahan et al., 2002). For instance, in the context of ICT revolution, studies have shown that firms are able to exploit gains from the introduction of new technologies when they have pre-existent organizational capabilities (cfr., Brynjolfsson and Hitt, 2000; Mairesse et al., 2001; Doms et al., 1997). At the same time, other studies point to negative effects of adopting ICT without corresponding changes in technical and organizational practices (cfr., Dosi et al., 2010b), supporting the presence of productivity constraints determined by firms capability accumulation.
} 
Therefore, the demand for capital goods is determined by the difference between desired and current production capacity, given the effective productivity of the previously selected vintage, $\bar{A}_{i t}^{v}$, i.e.

$$
I_{i t}=\left(\frac{\bar{Y}_{i t-1}}{\bar{\omega}}-\hat{Y}_{i t}\right) \frac{1}{\bar{A}_{i t}^{v}},
$$

where $\hat{Y}_{i t}=\sum_{v \in V_{i t}}(1-\delta) k_{i t}^{v} \bar{A}_{i t}^{v}$ is the current level of production capacity inherited from the past after the depreciation of capital at rate $\delta$. by

The law of motion for capital at the firm level, once taking into account the batch of heterogeneous machines, is given

$$
K_{i t+1}=\sum_{v=1}^{V_{i t}}(1-\delta) k_{i t}^{v}+I_{i t} .
$$

Price setting C-firms set the price by charging a mark-up, $\mu_{i t}$, on the unitary labor cost, i.e.

$$
p_{i t}=\left(1+\mu_{i t}\right) c_{i t} .
$$

with $c_{i t}=\frac{w_{t} N_{i t}}{Y_{i t}}$. According to surveys on price-setting behavior, mark-up pricing is the dominant strategy adopted by firms, especially in the presence of imperfect market competition which provides firms with some degree of market power (Fabiani et al., 2005; Alvarez et al., 2006).

Similarly to Dosi et al. (2010a), the mark-up is determined endogenously and updated every period depending on the firm's degree of market power, as manifested in its individual market share (Kalecki, 1942). In particular, the mark-up is set according to the following rule

$$
\mu_{i t}=\left\{\begin{array}{cc}
\mu_{i t-1}\left(1+\mu_{t}^{r}\right) & \text { if } f_{i t}>\overline{f_{t}} \& \Delta f_{i t}>0 \\
\mu_{i t-1}\left(1-\mu_{t}^{r}\right) & \text { if } f_{i t}<\overline{f_{t}} \text { or } \Delta f_{i t}<0 \\
\mu_{i t-1} & \text { otherwise. }
\end{array}\right.
$$

Equation (14) states that if the firm's market share, $f_{i t}$, is above (below) the average share, $\bar{f} t$, and increasing (or decreasing) with respect to the previous period, the mark-up will be adjusted by a positive (negative) number, $\mu_{t}^{r}$, randomly drawn from a Folded Normal distribution with parameters $\left(\mu_{F_{3}}, \sigma_{F N 3}^{2}\right)$. Note that mark-ups adjust more frequently downward than upward. This is in line with results from empirical surveys pointing to the presence of asymmetries in price reactions to cost versus demand factors (see Alvarez et al., 2006). In particular, it is shown that prices respond more strongly to cost increases rather than decreases, while they react more to a fall in demand than to a rise. Furthermore, both for the U.S. and Europe, the size of price cuts are, on average, slightly larger than that of price increases. One of the reasons for asymmetric price adjustments lies in the fact that firms do not want to jeopardize the long-term relationship they report to have with customers by increasing prices too much in response to demand shocks.

Profits, dividends and net worth When the consumption good market closes, C-firms compute profits as the sum of sales and nominal variation of inventories minus wage bill, capital depreciation, interest payments on loans, R\&D expenditure and inventories depreciation. ${ }^{7}$ If positive, the firm distributes a fraction div of surplus to the owner in the form of dividend, net of taxes. The gross and net profits equations thus read

$$
\begin{aligned}
& \pi_{i t}=p_{i t} Q_{i t}+\left(i n v_{i t} p_{i t}-i n v_{i t-1} p_{i t-1}\right)-w_{t} N_{i t}-\sum_{v \in V_{i t-1}} \delta p^{v} k^{v}-\hat{r}_{i t} L_{i t}-R D_{i t}-\delta^{i n v} i n v_{t-1} p_{i t-1}, \\
& \pi_{i t}^{\text {net }}=(1-\operatorname{div}) \pi_{i t} .
\end{aligned}
$$

Net profits (or losses) pile up to equity ${ }^{8}$, which evolves as

$$
E_{i t+1}=E_{i t}+\pi_{i t}^{\text {net }} .
$$

When the net worth turns negative or liquidity falls short of financial obligations, i.e., interests and debt installment, the firm goes bankrupt and exits the market. Given that, for simplicity, the number of firms is assumed to be constant over time, each bankrupted firm is substituted by a new entrant, recapitalized by means of the owner's wealth, while the cost of bad debt is born by bank's equity which is reduced accordingly.

\footnotetext{
7 With regards to the interest payments, the rate on loans set by the bank for a specific firm can vary over time, therefore $\hat{r}$ is the weighted average of past interest rates with time-varying weights. The reader is addressed to Assenza et al. (2015) for a detailed explanation.

${ }^{8}$ To check that the balance sheet identity holds in every period, we compare the level of net worth as computed in Eq. (17) with the one resulting from the difference between assets and liabilities. Firms' assets are given by the sum of capital value and liquidity, while liabilities consist in corporate debt. Liquidity is updated by taking into account all cash inflows and outflows, including debt installments, as shown in the Appendix.
} 


\subsubsection{Capital good firms}

Innovation and imitation K-firms produce heterogeneous machine tools using only labor according to a Make-to-Order plan, meaning that the production orders are based on C-firms' investment demand, with no inventory accumulation. Following Dosi et al. (2010a), each K-firm is characterized by a technology $\left(A_{j t+1}^{v}, B_{j t+1}^{k}\right)$, where the former represents the productivity associated with the machine tool produced by firm $j$, while the latter indicates the labor productivity of firm $j$ itself. Innovators strive to improve the 'quality' of their technologies and reduce the production costs. To do that, they invest a constant fraction, $\sigma^{k}$, of net profits in R\&D to be allocated between innovation and imitation activities, based on parameter $\chi \in(0,1)$, i.e.

$$
\begin{aligned}
& R D_{j t}=\sigma^{k} \pi_{j t-1}^{n e t}, \\
& I N_{j t}=(1-\chi) R D_{j t}, \\
& I M_{j t}=\chi R D_{j t} .
\end{aligned}
$$

In line with the evolutionary tradition of technical change (Nelson and Winter, 1982; Dosi et al., 2010a), innovation and imitation activities follow a two-step stochastic process.

The first step determines whether or not the firm has the opportunity to innovate and imitate, defined as a random drawn from a Bernoulli distribution, with parameters $\operatorname{Pr}_{j t}^{i n n}$ and $\operatorname{Pr}_{j t}^{i m i}$, i.e.

$$
\begin{aligned}
& \operatorname{Pr}_{j t}^{i n n}=1-e^{-\varsigma I N_{j t}}, \\
& \operatorname{Pr}_{j t}^{i m i}=1-e^{-\varsigma I M_{j t}},
\end{aligned}
$$

with $\zeta>0$. Hence, the probability to innovate and imitate is increasing with the scale of R\&D investment.

In the second step, firms having the opportunity to innovate draw from a Folded Normal distribution a pair of technological innovations $\left(\Delta_{A}, \Delta_{B}\right)$, defined as productivity gains of the respective production techniques, according to

$$
\begin{aligned}
& A_{j t+1}^{v}=A_{j t}^{v}\left(1+x_{j t} \Delta_{A}\right), \text { where } \Delta_{A} \sim F N_{1}\left(\mu_{F N_{1}}, \sigma_{F N_{1}}^{2}\right), \\
& B_{j t+1}^{k}=B_{j t}^{k}\left(1+x_{j t} \Delta_{B}\right), \text { where } \Delta_{B} \sim F N_{2}\left(\mu_{F N_{2}}, \sigma_{F N_{2}}^{2}\right) .
\end{aligned}
$$

Similarly to Cantner and Pyka (1998), in order to capture the role of past experience on the individual firm's innovative performance, we assume that the actual size of productivity gains is proportional to the firm's relative position in the technology distribution, i.e., $x_{j t}=f\left(\hat{A}_{j t}^{v}\right) .^{9}$

When a K-firm draws the opportunity to imitate, it will search among the $Z_{i m i}$ more technically advanced firms and randomly pick one of their technologies.

Finally, firms compare the outcomes from innovation and imitation processes and choose to produce the technique with the highest built-in productivity.

Labor demand To preserve the stock-flow consistency of the model, K-firms employ R\&D expenditures to hire workers at the prevailing market wage $w_{t}$. If labor demand is greater than current workforce, K-firms post job vacancies on the labor market to cover the gap. In the opposite case, K-firms can get rid of excess workers at zero costs.

Price setting Similarly to C-firms, capital good producers set the price by charging a mark-up over the unit cost of production $c_{j t}$, being the latter defined as market wage over labor productivity, $B_{j}^{k}$. Differently from C-firms, however, the mark-up of K-firms is assumed to be fixed, as in Dosi et al. (2010a). ${ }^{10}$ Hence, the capital good price is given by

$$
p_{j t}=\left(1+\mu^{k}\right) c_{j t}
$$

where $\bar{\mu}^{k}$ is the mark-up, constant and uniform across firms, while $c_{j t}=\frac{w_{t}}{B_{j}^{k}}$ is the firm's unit labor cost.

Profits, dividends and net worth Profits (or losses) are computed as the difference between sales and variable costs. If positive, K-firms distribute a fraction div of surplus to the owner in the form of dividend, net of taxes. The law of motion of equity for K-firms is then updated by net profits or, if negative, losses, i.e., $E_{j t+1}=E_{j t}+\pi_{j t}^{n e t}$.

\footnotetext{
${ }^{9}$ In comparing the role of different idiosyncratic learning processes on industrial dynamics, Dosi et al. (2017) propose a similar formulation where the advancements in productivity, rather than being purely stochastic, depend upon the extant relative competitiveness of firms.

10 The reason why we assume a fixed mark-up for K-firms is our focus on the interaction between market concentration and mark-up dynamics in the consumption good sector. Therefore, we try to keep the formalization of all other sectors as simple as possible. Nonetheless, we have checked the sensitivity of results to changing values of the exogenous mark-up and no significant differences were detected in the results.
} 


\subsection{Household sector}

The households sectors is composed by $W$ workers and $K$ capitalists. The capitalist is the single owner of either a consumption or a capital good firm, such that $K=F+N$. Each agent receives an after tax income, $Y_{h t}$, where

$$
Y_{h t}=\left\{\begin{array}{cl}
\left(1-\tau^{w}\right) w_{t} & \text { if employed worker, } \\
s w_{t} & \text { if unemployed worker, } \\
\left(1-\tau^{k}\right) d i v \cdot \pi_{f t-1} & \text { if capitalist receiving dividends }
\end{array}\right.
$$

where $h \in\{w, f\}$ indicates whether agent $h$ is a worker or a capitalist, with $f \in\{i, j\}$ for consumption and capital good producers, $\tau^{w}$ and $\tau^{k}$ are the tax rates on, respectively, labor and capital income, while $s$ is the unemployment subsidy rate, computed as a fraction of current wage. Workers supply one unit of labor in exchange for a wage. The latter is uniform across firms and evolves over time depending on the average productivity growth $g_{A_{t}}$ according to

$$
w_{t+1}=w_{t}\left(1+\alpha_{w} g_{A_{t}}\right)
$$

where $\alpha_{w}$ is a parameter determining the elasticity of nominal wage with respect to productivity.

Capital income is given by the sum of dividends that capitalists receive both from their own firms and the bank, split in equal shares amongst firms' owners.

The household's demand for consumption goods is a linear function of disposable income and financial wealth. Based on the well-known Keynesian principle according to which the saving rate is increasing along the income distribution, we assume that workers and capitalists have different propensities to consume out of income, namely $c_{w}$ and $c_{k}$, with $0<c_{k}<c_{w}<1$. Dynan et al. (2004) provides an empirical assessment of the propensities to save of individuals belonging to different quintiles and percentiles of the income distribution. The values of $c_{w}$ and $c_{k}$ that are adopted in this model are in line with those found by Dynan et al. (2004), under the assumption that the average worker belongs to the medium quintile of the distribution, while the average capitalist to the top $5 \% .{ }^{11}$ The resulting savings pile up to financial wealth, held in the form of bank deposits $D_{h t-1}$. The consumption budget can be specified as

$$
C_{h t}=c_{h}(1-\tau) Y_{h t}+c_{f} D_{h t-1}
$$

where $c_{h}=\left\{c_{w}, c_{k}\right\}$ and $0<c_{f}<1$ is the uniform propensity to consume out of wealth.

Having defined the consumption budget, the choice of the goods to buy is determined through the search-and-matching mechanism. Differently from the labor market, the partner's selection is not purely random, but is governed by a preferential attachment scheme, according to which consumers tend to be loyal to their previous seller. In particular, when the goods market opens, each household compares the price of the C-firm where she shopped in the previous period with the best price from $Z_{c}-1$ randomly visited firms. If the new price is lower than the old one, the consumer will switch to the new supplier with a certain probability, $P r_{s}$, which is increasing (in a non-linear way) with the price gap: the higher the percentage difference between $p_{\text {old }}$ and $p_{\text {new }}$, the higher the probability of switching to the new partner, as in

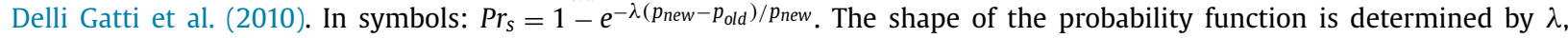
which represents the intensity of choice, i.e., how fast consumers switch to the most convenient supplier. It might happen that the amount of output supplied by the selected partner is lower than the household's demand for consumption goods. In this case, the consumer will resort to the other firms in the list, sorted in ascending order based on price.

\subsection{Banking sector}

The bank collects deposits from households and firms at zero interest rate and provides loans to C-firms to cover their financing gap, i.e., the production costs in excess of internal funds. ${ }^{12}$

After receiving the credit applications from borrowing firms, the bank sets the price and the quantity of loans for each borrower based on their financial situation.

First of all, the loan repayment schedule shall be defined. Let $\theta$ be the rate of reimbursement of outstanding debt. In each period $t$, the borrower repays a fraction $\theta(1-\theta)^{t}$ of the loan plus interests. Hence, the loan will be completely reimbursed only asymptotically on an infinite time horizon.

To compute the firm-specific interest rate, the bank estimates through a logistic regression the probability to default of the borrowing firm $i, p\left(l_{i t}\right)$, which is inversely proportional to the firm's leverage. The expected number of periods the firm will survive (i.e., time-to-default) is the reciprocal of the bankruptcy probability, i.e., $T T_{i t}=1 / p\left(l_{i t}\right)$.

Following Assenza et al. (2015), the interest rate charged by the bank to firm $i$ is derived from the arbitrage condition according to which the gross rate of return on lending, $R_{i t}$, is equal to the opportunity cost of lending, which, for simplicity, is assumed to be a multiple of the gross return on a risk-free asset, $\mu_{b} R$, where $0<\mu_{b}<1$.

\footnotetext{
${ }^{11}$ In particular, we set $c_{w}=0.90$ and $c_{k}=0.60$. Dynan et al. (2004) reports that the first quintile has a propensity to consume equal to $98.6 \%$, the medium $91 \%$, the last quintile equal to $76.4 \%$, while the top $5 \%$ consumes on average $62.8 \%$ of its income. For a critical review of the various theories of consumption in relation with income distribution, see Van Treeck (2014).

${ }^{12}$ The formalization of the credit market largely borrows from our parental model (Assenza et al., 2015), to which the reader is addressed for a detailed illustration. Here we limit ourselves to provide a summary overview of its essential features.
} 
In particular, given the amortization schedule presented above, the periodic payment that the bank expects to receive from the borrower - i.e., the gross rate of returns on lending to a risky firm - is given by

$$
R_{i t}=\sum_{t=0}^{T T_{i t}}\left(\theta+r_{i t}\right)(1-\theta)^{t}
$$

where $r_{i t}$ is the interest rate for firm $i$, which will be defined momentarily. Expanding the geometric series in Eq. (29) we get

$$
R_{i t}=\left(\theta+r_{i t}\right) \frac{1-(1-\theta)^{T T_{i t+1}}}{\theta}
$$

Using Eq. (30) and exploiting the arbitrage condition, the firm-specific interest rate is equal to ${ }^{13}$

$$
r_{i t}=\mu_{b}\left[\frac{1+\frac{r}{\theta}}{\Xi\left(\theta, T T_{i t}\right)}-\theta\right],
$$

where $\Xi\left(\theta, T T_{i t}\right)=1-(1-\theta)_{i t+1}^{T T}$. It can be noted that the interest rate is increasing with the risk-free rate and decreasing with the time to default, hence increasing with leverage.

In order to determine the supply of loans, the bank computes a tolerance level for the potential loss on credit as a fraction of its net worth, i.e., $\Gamma_{b t}=\phi E_{b t}$.

The bank sets a maximum amount of credit for each borrower, $L^{\text {max }}$, such that the expected loss on loans extended to firm $i$ is equal to the tolerance level, that is

$$
\left(L_{i t}^{\max }+L_{i t-1}\right) p\left(l_{i t}\right)=\Gamma_{b t}
$$

where $L_{i t-1}$ is the level of outstanding debt for firm $i$ at time $t$.

It follows that the bank may not be willing to fully satisfy firms' demand for loans. The actual loan is given by the minimum between firm's credit demand, $L_{i t}^{d}$, and the maximum amount of loan set by the bank, $L_{i t}^{\text {max }}$. In symbols,

$$
L_{i t}=\min \left(L_{i t}^{\max }, L_{i t}^{d}\right)
$$

According to Eq. (33), firms face a credit constraint whenever $L_{i t}^{d}>L_{i t}^{\max }$. In this case, they will be forced to re-scale the level of activity according to the liquidity available.

\subsection{Public sector}

The Government levies a constant tax rate on labor and capital income and pays out unemployment benefits to nonworking individuals. The unemployment subsidy is computed as a fraction, $s$, of the market wage. Whenever public expenditure exceeds tax revenues, the Government finances the resulting deficit by issuing Treasury bonds, bought by the Bank, at a fixed risk-free interest rate.

\section{Simulation results}

\subsection{Calibration and initialization}

To empirically validate the model, we follow a consolidated procedure in the macro ABM literature, also known as "output validation" (Delli Gatti et al., 2018). The goal is to establish a baseline scenario able to replicate a wide ensemble of empirical regularities at different levels of aggregation. The parameters' values employed in the model's equations are summarized in Table B.1 (in Appendix). Furthermore, another challenging task before resorting to computer simulations concerns the initialization of the model's variables. To comply with the stock-flow consistency principle, we require that the initial interrelated matrix of balance sheets among agents respects the double-entry bookkeeping system, according to which one agent's asset corresponds to someone else's liability. The initialization procedure involves the following steps:

- C-firms are endowed with an initial amount of capital goods such that aggregate output is associated with a desired rate of unemployment, i.e. 5\%, given the initial value of labor productivity, $A_{0}$, and the constant capital-labor ratio $\bar{l}$.

- The value of C-firms' liquidity, held in the form of bank deposits, is set equal to the value of capital stock. Since we assume there is no private debt at $t=1$, C-firms' net worth is given by the sum of capital value and liquid assets.

- Because K-firms use only labor, their net worth is simply equal to the value of liquidity, which is a fraction of C-firms' deposits.

- The financial wealth of households is held in the form of bank account and corresponds to 50 monthly wages, with $w_{1}=1$, in order to guarantee a sufficient saving buffer.

\footnotetext{
${ }^{13}$ Analogously, the gross rate on lending to a risk-free firm that survive for an infinite number of periods is $R=\left(1+\frac{r}{\theta}\right)$.
} 

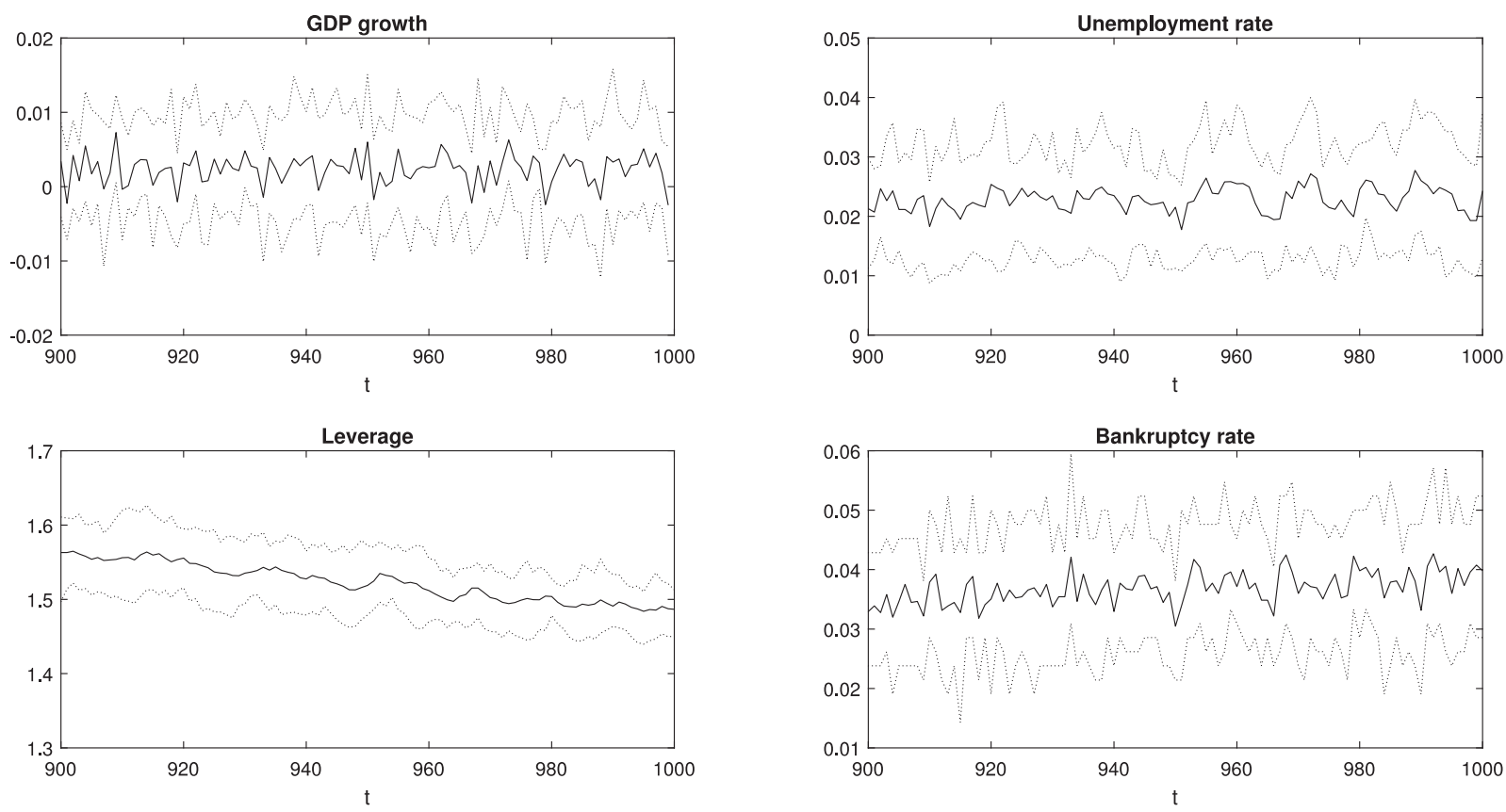

Fig. 2. Time series of cross-MC mean (and confidence interval) of selected macroeconomic variables. Last 100 periods are reported.

- Given that there are no initial corporate loans, the bank's balance sheet consists of Government bonds on the asset side and the sum of firms and households' deposits on the liabilities side. The initial stock of public bonds is a multiple of total deposits to make sure that the bank's equity is positive.

\subsection{Empirical validation}

Based on the parameter values and the initialization procedure described above, the empirical validation is performed by running a set of 25 Monte Carlo simulations with different random seeds for 1000 time periods. The artificial time series are constructed by taking averages across simulation runs and then compared with real data. Both simulated and real data are treated with the Hodrick-Prescott (HP) filter in order to isolate the cyclical component from the trend. The observed time series of GDP, consumption, investment and unemployment were downloaded from the FRED database and accounts for quarterly data for the U.S. ranging from Q1 1959 to Q4 2019. ${ }^{14}$

Figure 2 displays the last 100 periods for a selection of simulated time series. The model generates regular patterns in both real and financial sectors punctuated by persistent short-term fluctuations and recurrent bankruptcies.

To better appraise this figure, it is worth looking at the time series of trend and cyclical components separately, obtained after applying the HP filter to a set of macroeconomic variables, as shown in Fig. 3. The plot illustrates that, in line with the empirical evidence on business cycle (Stock and Watson, 1999), investment is systematically more volatile than GDP and consumption, with all of them growing at positive steady rates.

Following Assenza et al. (2015), Fig. 4 compares the autocorrelation and cross-correlation of GDP, consumption, investment and unemployment obtained from simulated data with their empirical counterparts. The autocorrelation structure of the two series look remarkably similar. The cross-correlation plots show that consumption and gross investment are procyclical with respect to GDP, while unemployment rate is anti-cyclical, as evidenced in observed data. From this validation exercise, we can safely say that the model does a fairly good job at reproducing the selected empirical regularities for the U.S. economy.

\subsection{Economic analysis}

Given the complex structure of interaction amongst heterogeneous agents and the multiple non-linear dynamic equations, the model does not lead to a closed-form analytical solution. Hence, to address our research question, we resort to the tool of computer simulations. The main goal of this paper is to analyze the underlying causes of the endogenous formation of market concentration and the resulting macroeconomic consequences, both in the short and long run. Thus, we first highlight the mechanisms behind the emergent dynamics of the model from one representative simulation. Afterwards, we perform Monte Carlo simulations to examine the long-term macroeconomic dynamics.

\footnotetext{
${ }^{14}$ We take the last observation available before the outbreak of Covid-19 pandemic for it would add excessive volatility to the empirical data.
} 

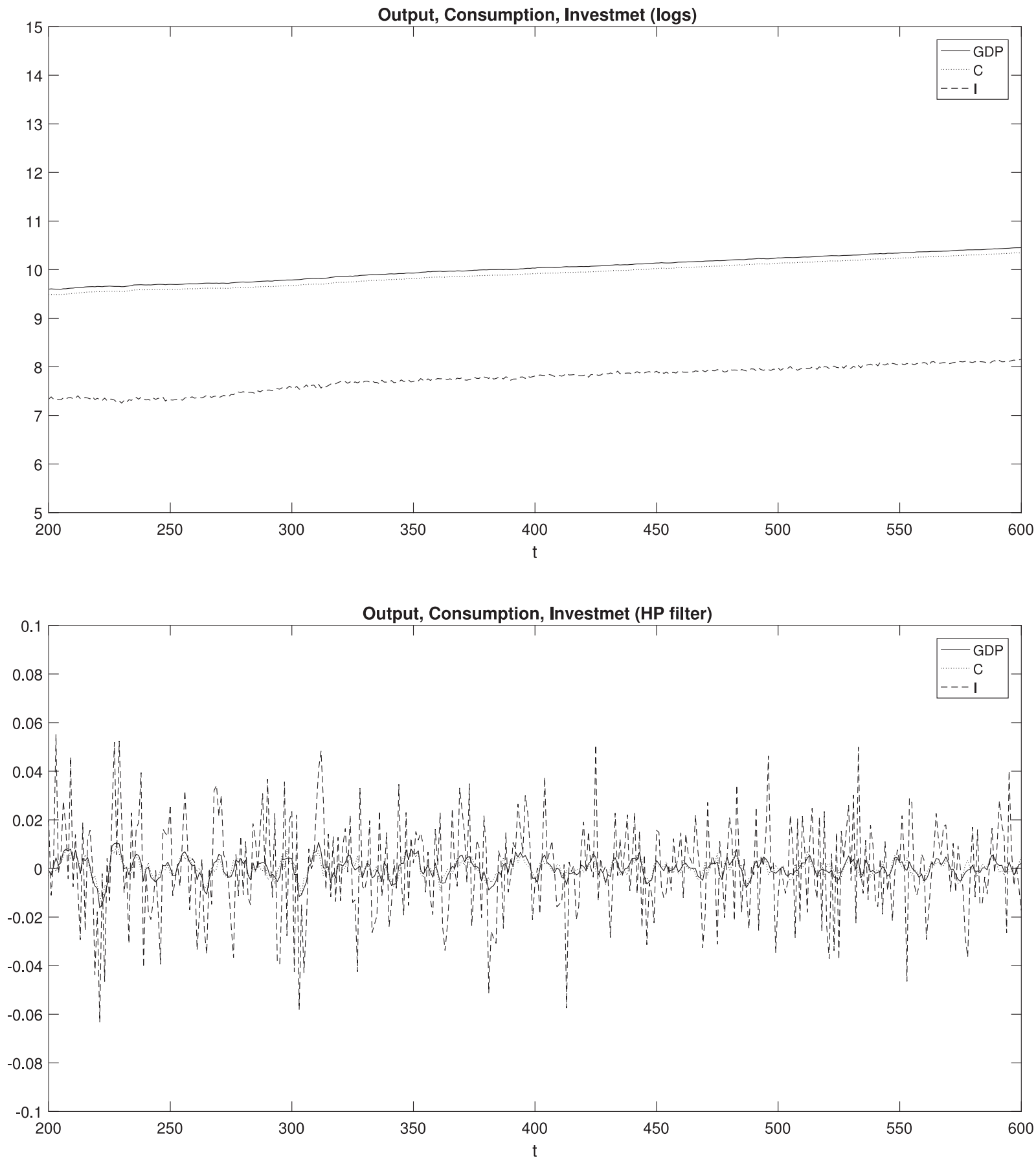

Fig. 3. Cross-MC average of real GDP, consumption and investment. Trend and cyclical components are obtained by applying the HP filter.

\subsubsection{The story of concentration: a short run focus}

Figure 5 collects a set of plots displaying the time series of both aggregate and firm-level variables in the first 250 periods from one representative simulation of the model. This allows us to dig into the microeconomic mechanisms underlying the macroeconomic dynamics.

In every simulation run, after a short period of transition, the model endogenously generates a wave of market concentration, that is a situation in which a relatively small number of firms ends up holding a vast share of the market, causing a sharp increase in the Herfindahl-Hirschman index. From the left-hand panels, we notice that the process of concentration is determined by a reallocation of market shares towards more productive and knowledge-intensive firms. The leaders, in 

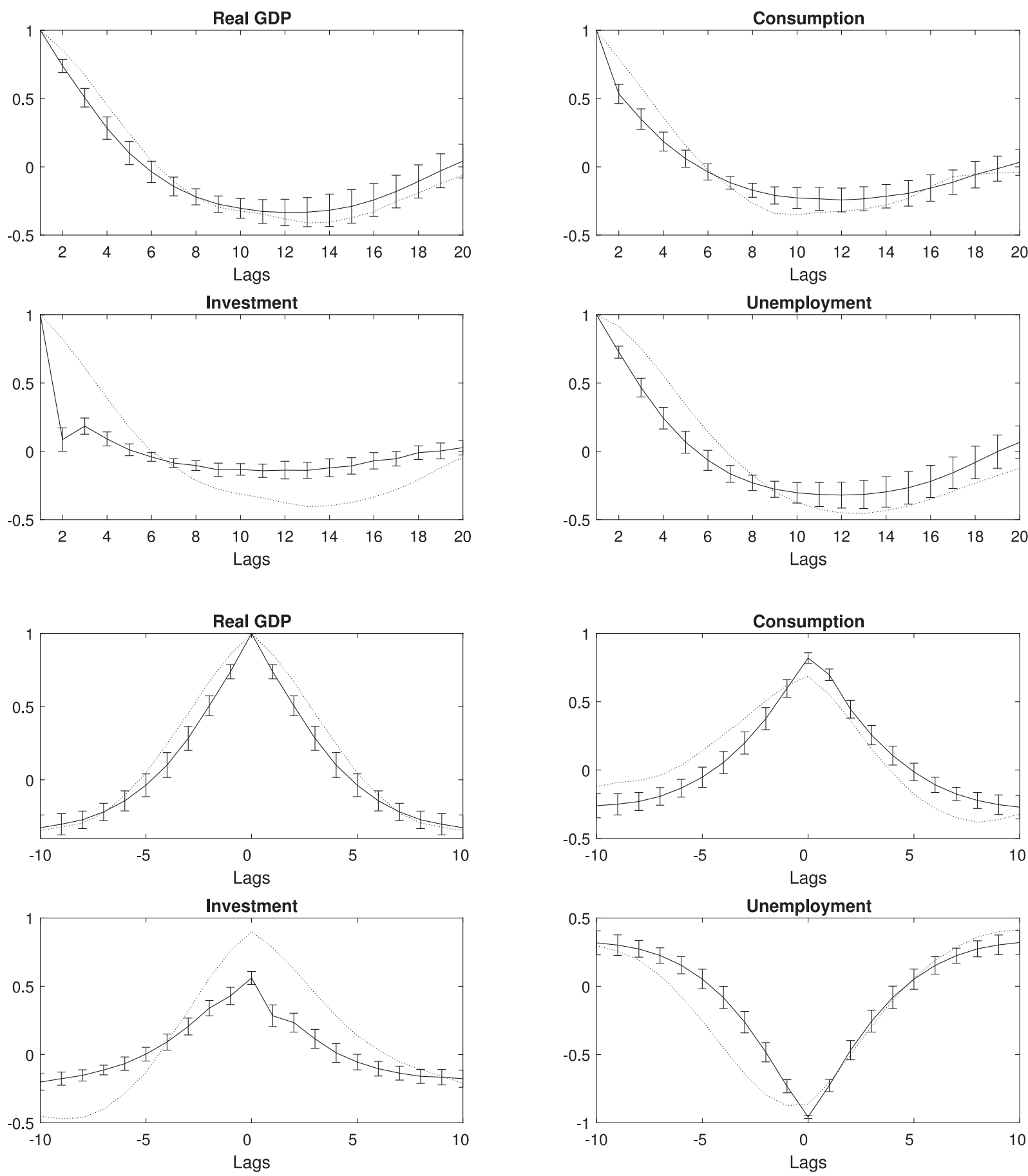

Fig. 4. Autocorrelation (top) and cross-correlation (bottom) of GDP, consumption, investment and unemployment for simulated (solid line) and empirical (dashed line) data. All variables are treated with the HP filter to isolate the cyclical component.

fact, are those firms that manage to use their accumulated technical knowledge to invest in more efficient machines, thus achieving faster productivity gains and large market shares. This outcome is reminiscent of the notion of "superstar" firms by Autor et al. (2020). Yet, while the basic assumption of their standard model is that firms are endowed with different productivity levels, in our agent-based model superstar firms endogenously emerge from the bottom up, without resorting to different initial conditions. In the jargon of complexity theory, this is an emergent property of the system. In fact, the source of concentration lies in the fact that firms do not have equal access to capital-embodied innovation, as this depends on the "knowledge gap": in the capital goods market, firms with greater technological knowledge are more likely 

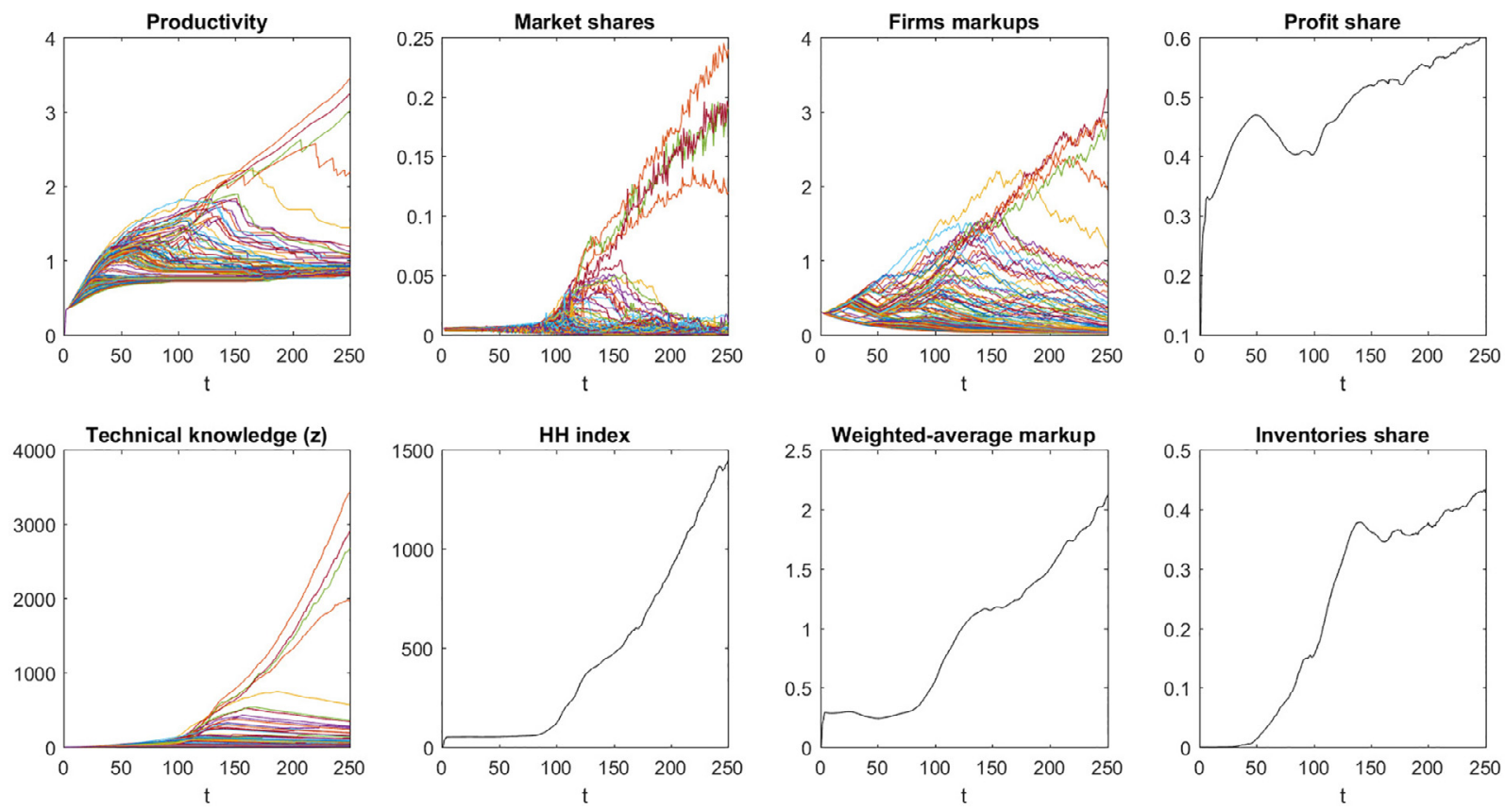

Fig. 5. Dynamics of selected aggregate and firm-level variables; first 250 periods from one representative simulation.

to choose the best vintages of capital goods. It follows that, in the absence of consistent knowledge spillovers and as long as capital goods remain considerably different from each other, technical progress that generates "technological discontinuities" (Sylos Labini, 1967), as reflected in the growing differentials in productivity across C-firms, thus resulting in a higher industry concentration.

Having explored the underlying causes of rising concentration, let us now shift the focus on the second half of the story, that is the macroeconomic consequences. From the right-hand panels in Fig. 5, it can be seen that firms with larger market shares are able to increase their profit margins. Remind from the pricing rule in Eq. (14) that the mark-up is set according to the firm's degree of monopoly power. In particular, one firm adaptively reviews the mark-up upwards if its market share is high and increasing over time. This is evidently the case for leading firms, which, thanks to the improved productive capacity and low unitary costs, can raise their mark-ups without incurring in a loss of market share. Moreover, as the weight of large firms grows over the economy, the increase in the weighted-average mark-up, adjusted by individual shares, leads to an increase in the profit share. In so far as wage and profit earners have different marginal propensities to consume, a redistribution of income from the bottom to the top implies a decline in the aggregate consumption, as reflected in the rising share of unsold goods (bottom-right panel).

Following the lessons from Sylos Labini (1967) and Steindl (1976), therefore, the economic system may spontaneously reach a state of underconsumption as a result of changes in market structure and income distribution, triggered by technical progress and market power. As Steindl (1976) put it, "[t]he tendencies towards oligopoly discovered at the microeconomic level will cause a tendency towards stagnation at the macroeconomic level.g

\subsubsection{Long-term macroeconomic trends: the role of legal entry barriers}

It has been shown that, in the early stage of a representative simulation, the model endogenously generates a wave of market concentration, driven by technical change, which impacts on income distribution and economic dynamics. A natural question is: what happens next?

To explore the model properties in the long run, we confront the baseline model with an alternative scenario in which K-firms are not allowed to imitate. More specifically, the parameter $\chi$ in Eq. (20) is set equal to 0 (from 0.5 ) so that the entire R\&D budget is spent on innovation. We can think of the alternative scenario as a situation in which a strict innovation patent system is in place, whereby legal entry barriers prevent K-firms from imitating their competitors' technologies. This simulation experiment allows us to fully appraise the role of both knowledge gap and technological discontinuities on the process of market concentration and its long-term effects on the economic performance.

Before looking at the model dynamics at the aggregate level, it is worth dwelling on the dynamics of K-goods' technology and C-firms' productivity from one representative simulation. Figure 6 shows that the imitation activity carried out by Kfirms brings about a rapid convergence in the capital goods' productivity (a-left), causing a significant reduction in the technological discontinuities among C-firms (b-left). On the other hand, in the no-imitation scenario, such a convergence 

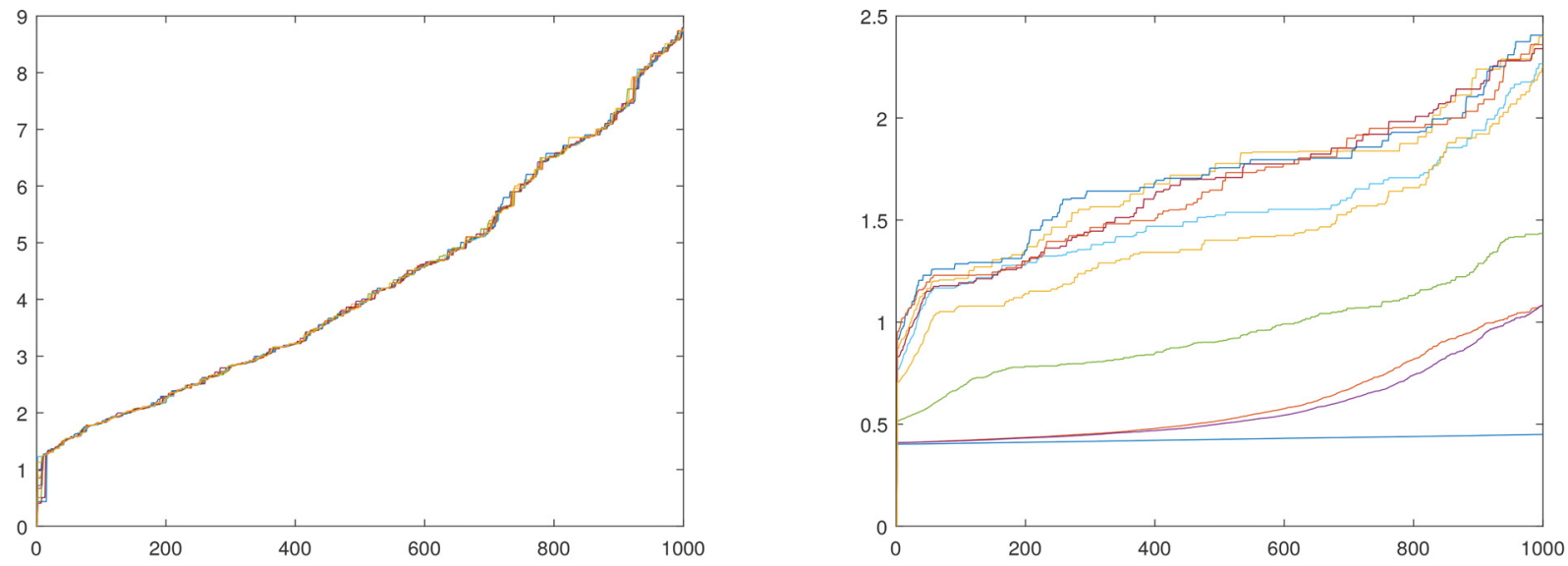

(a) Vintage quality of K-firms
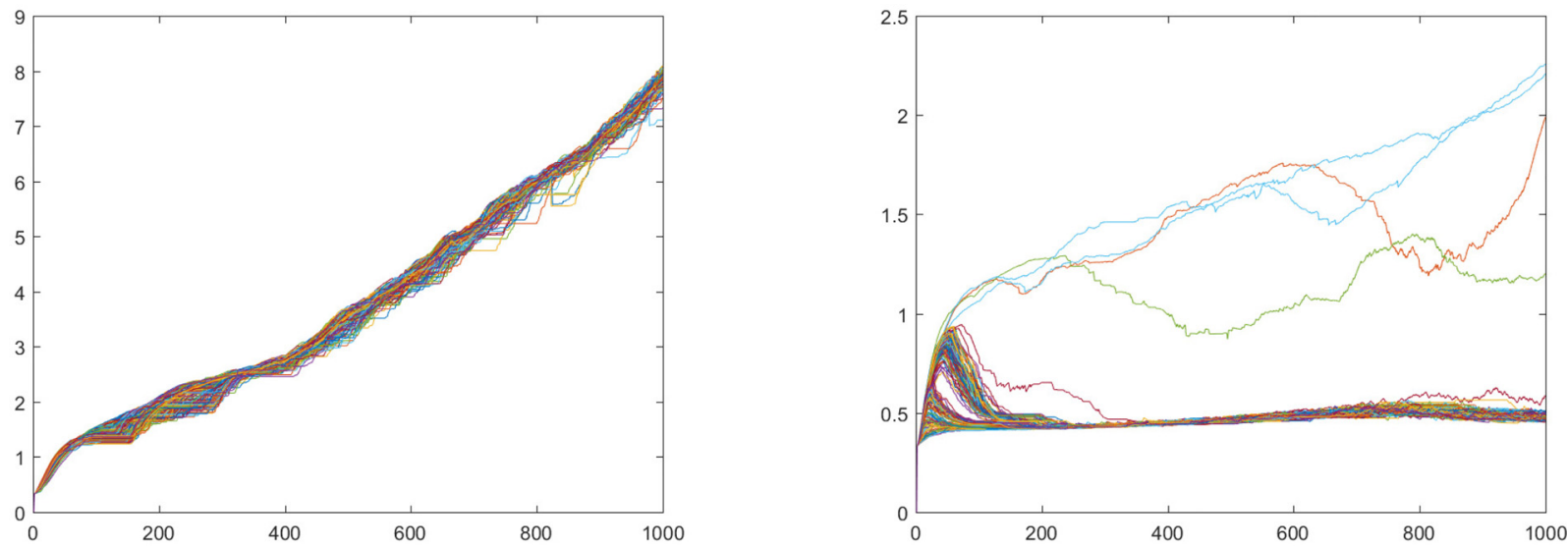

(b) Labor productivity of C-firms

Fig. 6. Comparison of vintage quantity by K-firms and labour productivity by C-firms between imitation (left) and no-imitation (right) scenarios from one single simulation.

does not occur and, consequently, the persistent heterogeneity between capital goods is reflected in the growing differences in productivity across C-firms (b-right).

Interestingly, it emerges that a strict correlation exists between the technological evolution in the capital good sector and firm size distribution in the consumption good sector: in presence of relatively homogeneous capital goods due to the imitation activity by K-firms, large firms in the C-sector are not able to exploit their "knowledge advantage" to buy relatively more efficient techniques than their competitors, allowing the laggards to catch up. Conversely, a persistent heterogeneity among capital goods makes the "knowledge gap" mechanism more effective, resulting in higher differences in size and productivity across C-firms.

The differences in the technological structure across C-firms are reflected in the evolution of unit costs, mark-ups and prices displayed in Fig. 7. Here the population of firms is split in two groups with respect to size, where large (small) firms belong to the upper (lower) 10th quantile of the sale distribution. In both scenarios, the rise in technological discontinuities that occurs during the initial wave of concentration generates a discrepancy in costs and mark-ups among firms. Then, whereas such differences are soon re-absorbed when imitation is allowed (left-hand panels), in the no-imitation scenario (right-hand panels) large and small firms experience two diverging trends determined by the increasing differences in the technological structure. On the one hand, small firms face rising unit costs due to weak productivity gains in spite of accelerating wage growth. On the other hand, large firms can exploit the low unitary costs stemming from technical advancements to set higher mark-ups without this translating into a loss of market shares.

The same pattern emerges by looking at the evolution of market structure over time. Figure 8 illustrates the cross-MC average distribution of firm size measured in terms of output and number of employees in different time periods of the 

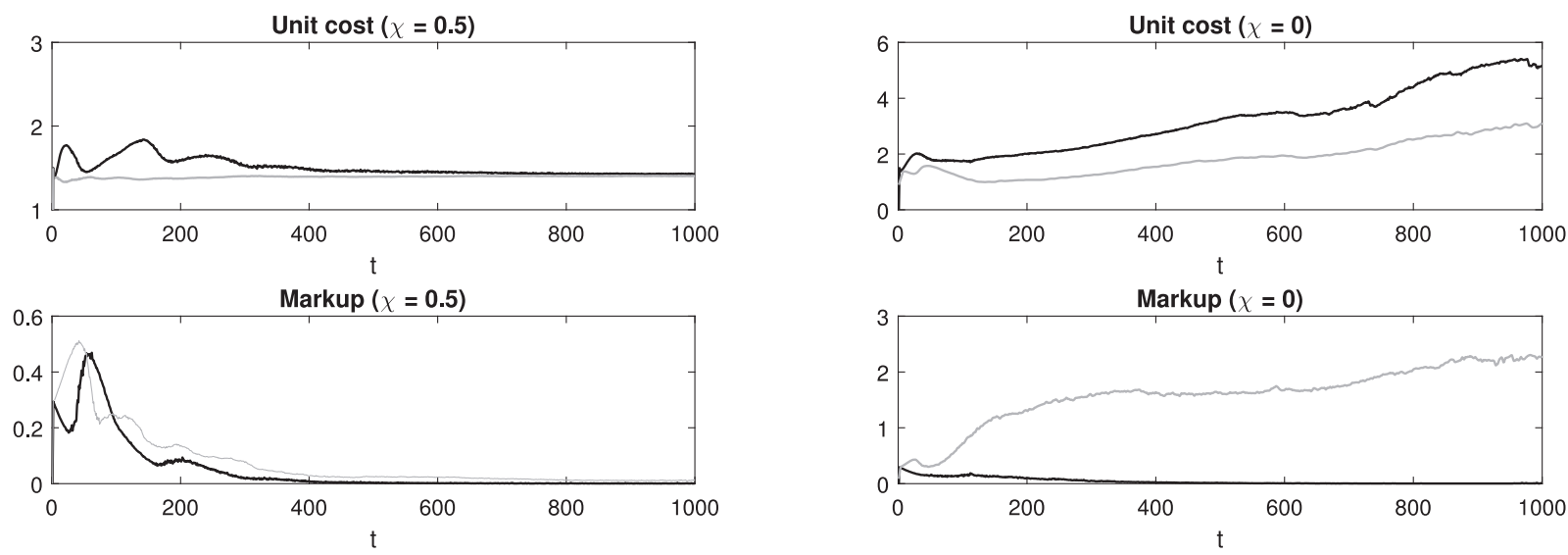

Price $(\chi=0.5)$

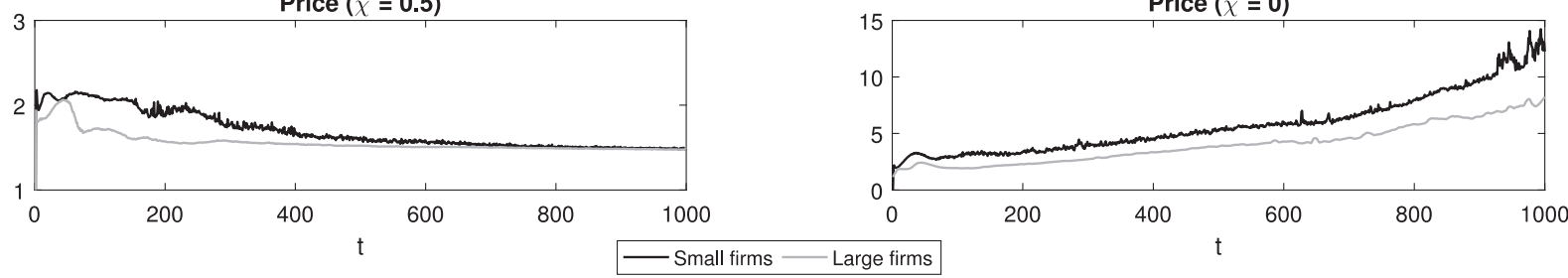

Fig. 7. Evolution of unit costs, mark-ups and price of large (grey) and small (black) firms in the imitation (left-hand) and no-imitation (right-hand) scenario. Mean values across 25 Monte Carlo simulations.
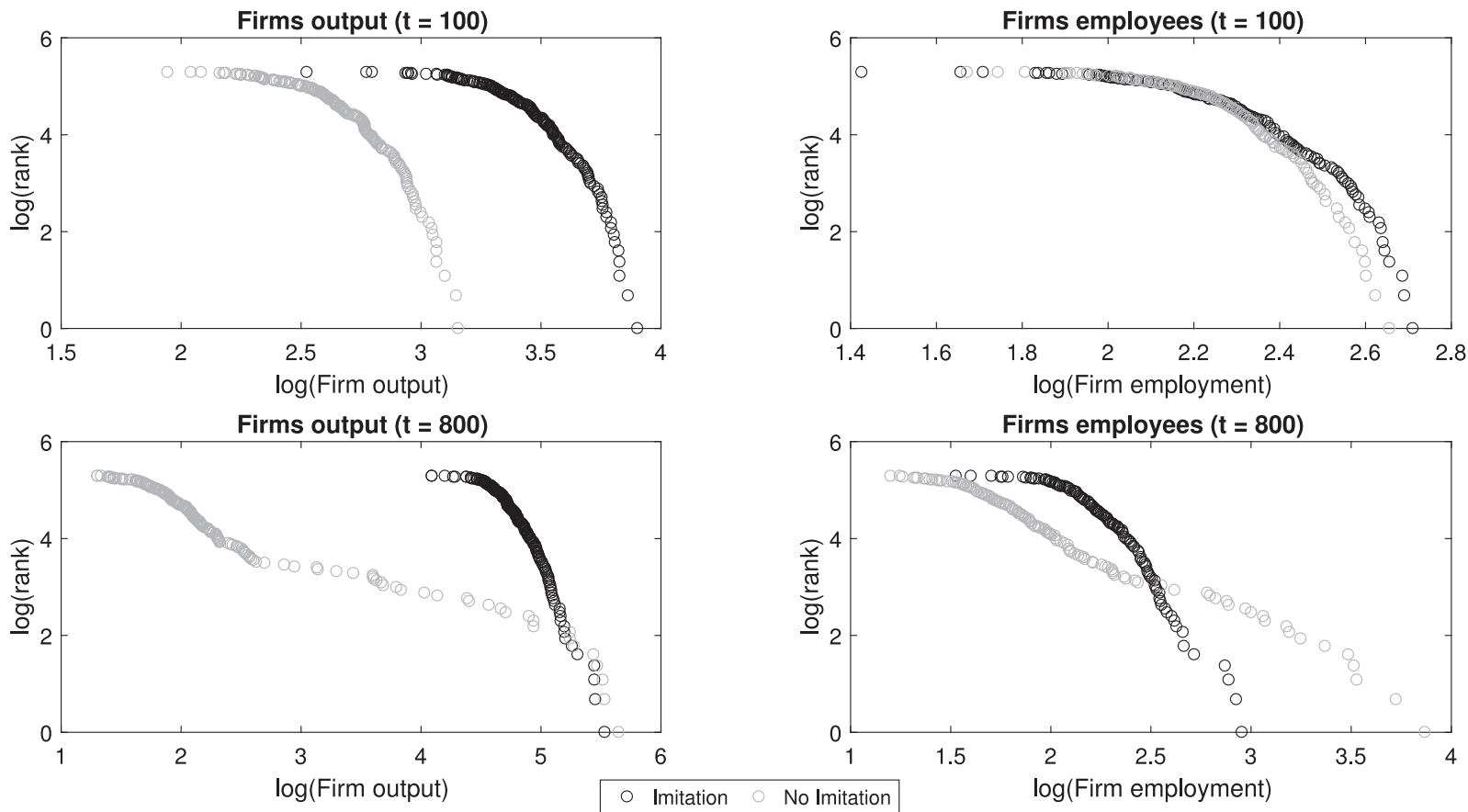

Fig. 8. Distribution of firms size in terms of output and number of employees at $t=100$ (top half) and $t=800$ (bottom half) in the imitation (black) and no-imitation (grey) scenario. Mean values across 25 Monte Carlo simulations.

simulation, i.e., $t=100,800$; at the selected time, for each rank the mean value of the considered variables across runs is depicted on a log-log scale. Comparing the two scenarios, we observe that, after 100 periods (top panels), in the midst of the first concentration wave, the firm size distribution exhibits similar properties in terms of fat tails and substantial heterogeneity for both variables. As time passes, however, the baseline scenario with imitation is characterized by more homogeneous firms, while the firm size distribution becomes even more skewed in the alternative scenario, especially with regard to firms output, while somewhat lower in terms of number of employees. This means that there is a smaller number 

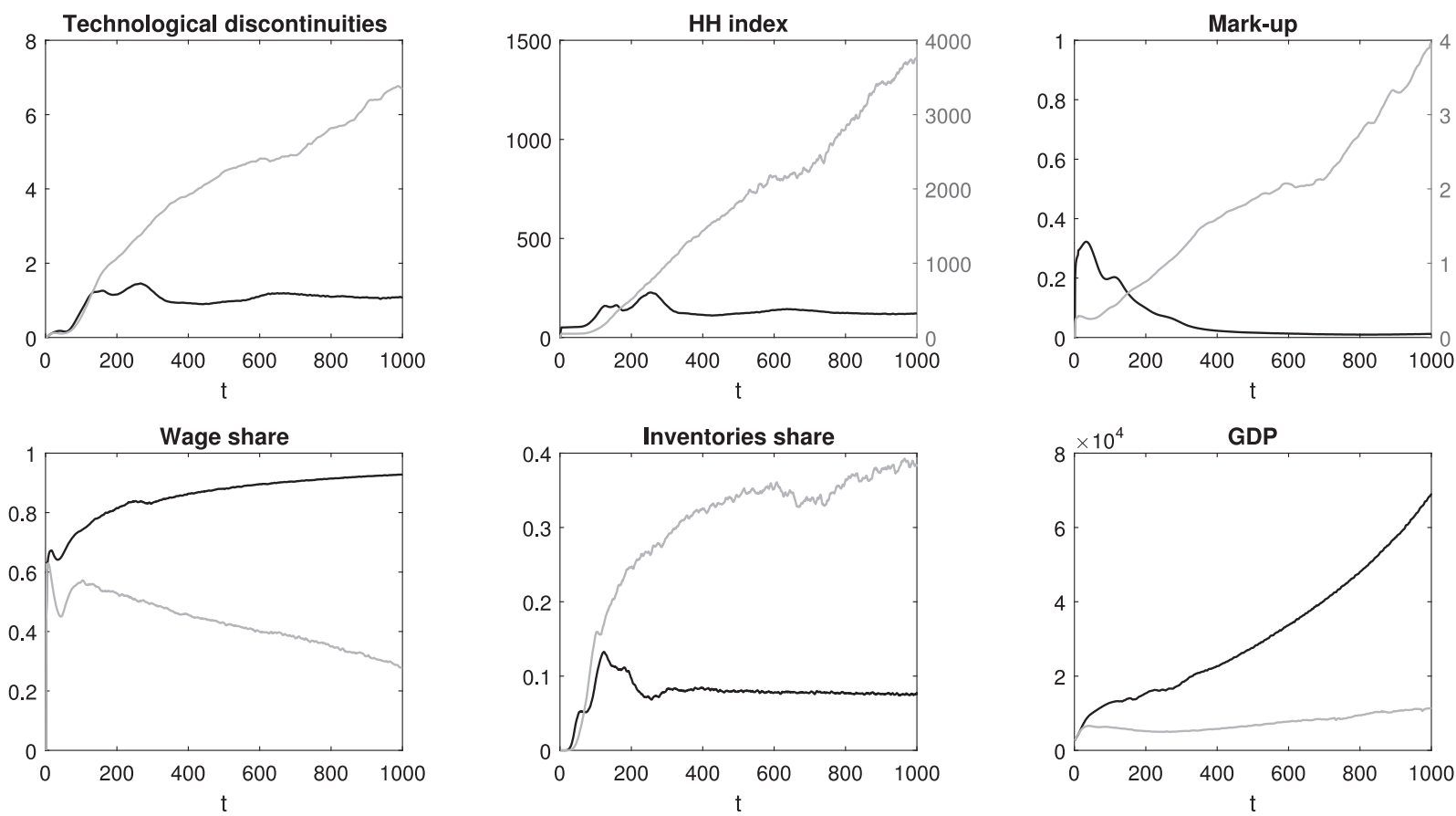

Fig. 9. Time series of selected macro variables in the imitation (black) and no-imitation (gray) scenario. Mean values across 25 simulations.

of firms producing increasingly larger output levels with relatively small workforce. A similar trend can be observed in real data for the U.S. economy. For instance, Autor et al. (2017) find that sales concentration has gone hand-in-hand with employment concentration, which also increased but less than proportionally, suggesting that firms achieve larger market shares by employing a lower share of workers. In fact, "the industries that are becoming more concentrated are those with faster growth of productivity and innovation" (Autor et al., 2017).

It will soon become clear that such differences in the technological patterns across firms and sectors entail important macroeconomic consequences in terms of income distribution and economic growth. Figure 9 collects a set of plots displaying aggregate time series, averaged across 25 Monte Carlo repetitions, for both imitation and no-imitation scenario. In this way, we are able to assess the role of legal entry barriers on macroeconomic dynamics in the longer run.

It can be seen that, after the initial wave of market concentration, in the imitation scenario (black curve), the economy quickly returns to a competitive stage, characterized by low $\mathrm{HH}$ index and mark-up, as well as high wage share and consumption. By contrast, when imitation is not allowed (red curve), the process of market concentration experiences a growing trend, driven by rising technological discontinuities ${ }^{15}$, and results in an steady increase in the average mark-up, profit and inventories share, while GDP is remarkably lower compared to the baseline scenario. The evolution of market concentration over time, thus, depends on the corporate sector's ability to reproduce technological discontinuities within the system, which, in turn, is related to the process of diffusion of technological innovations amongst K-firms and, subsequently, to the C-firms' ability to consolidate their position by exploiting knowledge differentials.

Indeed, by reducing the knowledge gap with respect to all machine tools available on the market, the convergence between heterogeneous capital goods brought about by the imitation activity by K-firms undermines the dominant position of oligopolistic firms, which eventually loose their market power and thus their ability to extract larger rents. As a result, the ensuing reduction in income inequality strengthens aggregate demand and fosters a competitive and self-sustained growth process. Such a counter-tendency does not occur in the no-imitation scenario. In this case, in fact, the persistent character of technological discontinuities enables giant firms to consolidate their dominant position and exploit the enhanced market power, with negative effects on income distribution and aggregate demand also in the long run.

Table 1 provides a quantitative comparison of the model outcomes under different scenarios. We can see that, in the presence of legal barriers to imitation, the concentration index is nearly one order of magnitude higher than in the baseline scenario, which implies a higher mark-up and a lower output growth. Also, under the no-imitation scenario, the chronic excess capacity due to lower demand leads to a twice higher unemployment rate and, consequently, an increase in the

\footnotetext{
${ }^{15}$ The variable technological discontinuities is calculated as the ratio between the standard deviation of labor productivity for C-firms over the average industry productivity.
} 
Table 1

Statistics for selected variables in the imitation and no-imitation scenarios: cross-MC mean and standard deviation (in parenthesis)

\begin{tabular}{lll}
\hline & Imitation & No Imitation \\
\hline GDP growth rate (\%) & 0.332 & 0.172 \\
& $(0.0001)$ & $(0.0008)$ \\
Capacity utilization & 0.80 & 0.657 \\
& $(0.0045)$ & $(0.0381)$ \\
Unemployment rate & 0.043 & 0.107 \\
& $(0.0058)$ & $(0.0995)$ \\
HH index & 128.425 & 1738.087 \\
& $(0.1295)$ & $(16.0168)$ \\
Mark-up & 0.060 & 1.808 \\
& $(0.0074)$ & $(1.4875)$ \\
Profit share & 0.145 & 0.57 \\
Inventories/GDP & $(0.0061)$ & $(0.1093)$ \\
Public deficit/GDP & 0.078 & 0.294 \\
Public debt/GDP & $(0.0040)$ & $(0.1385)$ \\
Leverage & 0.03 & 0.175 \\
Bankruptcy rate & $(0.0039)$ & $(0.0697)$ \\
& 1.362 & 4.969 \\
& $(0.0973)$ & $(2.3605)$ \\
& 1.696 & 1.582 \\
& $(0.0629)$ & $(0.4415)$ \\
& 0.028 & 0.049 \\
& $(0.0030)$ & $(0.0300)$ \\
\hline
\end{tabular}

public deficit (and debt) over GDP ratio. ${ }^{16}$ In line with Sylos Labini (1967) and Steindl (1976), our findings suggest that the tendency to stagnation arising from an oligopolistic market structure requires a more expansionary fiscal policy. In other words, the economic system is increasingly dependent on external stimuli to compensate for the structural deficiency in aggregate demand due to the unequal distribution of income. Albeit from a different framework, the modern theorists of the 'new secular stagnation' hypothesis reach remarkably similar policy conclusions. ${ }^{17}$ We will further explore the role of economic policy in the next Section.

Finally, it is interesting to note that despite aggregate leverage being somewhat lower in the no-imitation scenario, the rate of bankruptcy is twice as high. This is due to the recurring defaults by a considerable number of small unproductive firms which fail to catch up with the leaders. Yet, the level of corporate debt for these firms is relatively small since they face weak growth opportunities. On the other hand, large firms are able to finance investment projects mainly through internal resources thanks to the improving financial conditions. As a result, the concentrated economy is characterized by a lower leverage but a higher bankruptcy rate.

\subsection{Policy experiments}

This section aims at identifying which policies or institutional regimes might be potentially able to attenuate the concentration dynamics and/or to curb the resulting stagnation tendency. In particular, we carry out a labor market policy to further explore the nexus between inequality, innovation and growth. Moreover, we examine through an innovation policy how the process of diffusion of technological knowledge affects industry concentration and GDP. For each policy experiment, we run 25 simulation runs with different random seeds. The cross-MC averages for selected variables are collected in Table 2 and compared with the baseline scenario, the one with imitation activity (i.e., $\chi=0.5$ ).

Labor market policy. We start with a labor market reform aimed at weakening trade unions power. This is captured by a reduction in parameter $\alpha_{w}$ governing the wage-productivity elasticity in Eq. (27), i.e., the degree to which the nominal wage responds to a change in productivity. As in Dosi et al. (2010a), in the baseline scenario we have $\alpha_{w}=1$, meaning that trade unions are able to fully pass on any increase in productivity to nominal wages. In Experiment 1.1 , we set $\alpha_{w}=0.90$.

We find that a weaker labor union leads to higher mark-ups and fosters a profit-led growth. This should not come as a surprise in that in our model R\&D investment, which affects the probability to innovate and imitate for K-firms as well as the accumulation of technological knowledge for C-firms, is a function of realized profits, contrary to, e.g., Dosi et al. (2010a) where R\&D depends on past sales. This makes the relationship between demand, distribution, innovation and growth less trivial. It should also be noted that the enhanced output growth comes at the cost of a higher unemployment rate. By fostering the adoption of more efficient techniques, in fact, technical progress forces a considerable fraction of

\footnotetext{
16 Note that, in these simulation settings, the Government is not subject to any fiscal constraints: public budget is left free to adapt to business fluctuations and the resulting public bonds are entirely purchased by the Bank. In the next Section, the effects of alternative policy regimes will be explored.

17 See Summers (2014) and Krugman (2014) for a discussion about the secular stagnation hypothesis. For a critical review of its neoclassical theoretical underpinning, see Di Bucchianico (2020).
} 


\section{Table 2}

Cross-simulation mean and standard deviation (in parenthesis) for selected variables under different policy regimes. A two-sample $t$-test for equal means with respect to the baseline model is performed: the symbol * indicates that the null hypothesis is not rejected. Variables description: GDP gr., growth rate of GDP; GDP std. GDP volatility; $U$, unemployment rate; $H H$, Herfindahl-Hirschman index; Avg. Mu, weighted-average mark-up; $\Pi / G D P$, profit share; GDP ly, GDP level in the last simulation period compare to the baseline; C/GDP, consumption share; Inv/GDP, inventories share; Def/GDP, public deficit-GDP ratio.

\begin{tabular}{|c|c|c|c|c|c|c|c|c|c|}
\hline Policy experiment & GDP gr. & GDP std. & $\mathrm{U}$ & $\mathrm{HH}$ & Mark-up & $\Pi / G D P$ & GDP_ly & Inv/GDP & Def/GDP \\
\hline 0. Baseline & $\begin{array}{l}0.3317 \\
(0.0001)\end{array}$ & $\begin{array}{l}0.0144 \\
(0.0006)\end{array}$ & $\begin{array}{l}0.0434 \\
(0.0058)\end{array}$ & $\begin{array}{l}128.553 \\
(0.1295)\end{array}$ & $\begin{array}{l}0.0597 \\
(0.0075)\end{array}$ & $\begin{array}{l}0.1439 \\
(0.0062)\end{array}$ & 1 & $\begin{array}{l}0.0777 \\
(0.0041)\end{array}$ & $\begin{array}{l}0.0304 \\
(0.0040)\end{array}$ \\
\hline \multicolumn{10}{|l|}{ 1. Labor market policy } \\
\hline 1.1 Weak labor unions & $\begin{array}{l}0.3436^{*} \\
(0.0003)\end{array}$ & $\begin{array}{l}0.0180 \\
(0.0008)\end{array}$ & $\begin{array}{l}0.2159 \\
(0.0319)\end{array}$ & $\begin{array}{l}114.423 \\
(0.0599)\end{array}$ & $\begin{array}{l}0.5147 \\
(0.1189)\end{array}$ & $\begin{array}{l}0.3154 \\
(0.0318)\end{array}$ & 1.0988 & $\begin{array}{l}0.1342 \\
(0.0168)\end{array}$ & $\begin{array}{l}0.1685 \\
(0.0126)\end{array}$ \\
\hline 1.2 Weak labor unions + no subsidy & $\begin{array}{l}0.099 \\
(0.0003)\end{array}$ & $\begin{array}{l}0.0269 \\
(0.0028)\end{array}$ & $\begin{array}{l}0.6675 \\
(0.0523)\end{array}$ & $\begin{array}{l}130.784^{*} \\
(0.1740)\end{array}$ & $\begin{array}{l}0.1954 \\
(0.1697)\end{array}$ & $\begin{array}{l}0.2323 \\
(0.0486)\end{array}$ & 0.0792 & $\begin{array}{l}0.0583 \\
(0.0265)\end{array}$ & $\begin{array}{l}0.6288 \\
(0.1889)\end{array}$ \\
\hline \multicolumn{10}{|l|}{ 2. Innovation policy } \\
\hline 2.1 High knowledge spillovers & $\begin{array}{l}0.3373^{*} \\
(0.0002)\end{array}$ & $\begin{array}{l}0.0147 \\
(0.0008)\end{array}$ & $\begin{array}{l}0.0453^{*} \\
(0.0068)\end{array}$ & $\begin{array}{l}131.38^{*} \\
(0.1381)\end{array}$ & $\begin{array}{l}0.0597 * \\
(0.0077)\end{array}$ & $\begin{array}{l}0.1408^{*} \\
(0.0059)\end{array}$ & 1.056 & $\begin{array}{l}0.0759^{*} \\
(0.0038)\end{array}$ & $\begin{array}{l}0.0301 \\
(0.0036)\end{array}$ \\
\hline 2.1 High knowledge spillovers + ex. AC & $\begin{array}{l}0.5221 \\
(0.0003)\end{array}$ & $\begin{array}{l}0.0167 \\
(0.0005)\end{array}$ & $\begin{array}{l}0.0740 \\
(0.0055)\end{array}$ & $\begin{array}{l}202.094 \\
(0.2021)\end{array}$ & $\begin{array}{l}0.0576^{*} \\
(0.0028)\end{array}$ & $\begin{array}{l}0.1130 \\
(0.0042)\end{array}$ & 6.600 & $\begin{array}{l}0.0568 \\
(0.0025)\end{array}$ & $\begin{array}{l}0.0237 \\
(0.0017)\end{array}$ \\
\hline
\end{tabular}

workers out of the production process, which is not fully re-absorbed because of the slowdown in wages and demand. The drop in employment, however, does not impair the growth process because the resulting expansion of public deficit meant to finance unemployment subsidies provides support to aggregate demand. ${ }^{18}$ To assess the role of fiscal policy in a weak labor union environment we replicate the experiment by shutting off the Government spending on unemployment subsidies. In this case (Experiment 1.2), the economy experiences a collapse in GDP and employment, higher output volatility and, despite the lack of unemployment benefits, an explosion of public deficit due to interest payments on (initial) outstanding bonds and declining tax revenues. Hence, this experiment shows that in presence of weak labor unions, fiscal policy is essential to support aggregate demand and thus guarantee a profit-led growth, otherwise the economy would remain stuck in a high unemployment-low growth trap. ${ }^{19}$

Innovation policy. We now want to get further insights on the process of knowledge accumulation, which, as seen in the previous section, plays a fundamental role in the choice of capital vintage, thus influencing the emergence of technological discontinuities and market concentration. First of all, we examine the effects of a change in the degree of intra-industry knowledge spillovers, represented by $\psi$ in Eq. (6). This parameter captures the extent to which other firms' R\&D effort affects the accumulation of technological knowledge by the individual firm. In other words, a high value of $\psi$ means that the R\&D activity carried out by one firm increases the pool of technological knowledge available to all firms (Cohen and Levinthal, 1989).

In the first high-knowledge spillover policy (Experiment 2.1), $\psi$ is increased from 0.1 (benchmark value) to 1. Unsurprisingly, this policy does not entail any significant effect on the model outcomes. This is because, in such a scenario, the ability to exploit outside knowledge spillovers, i.e., the absorptive capacity, is still endogenous to firms' R\&D experience, as shown in Eq. (7): notwithstanding the availability of technological information, in presence of an endogenous absorptive capacity, smaller firms do not have the necessary technical skills to exploit them, failing to reduce the technology distance from the leaders.

For the sake of completeness, we investigate the effects of the same innovation policy under an institutional regime characterized by exogenous absorptive capacity $(\gamma=1)$. We can think of it as a (hypothetical) situation in which all firms not only have access to the same pool of technological information, but are also endowed with the necessary technical ability to process them, so that knowledge differentials substantially disappear. In such a scenario (Experiment 2.2), an high-knowledge spillover policy has a significant positive impact on the economy in terms of higher GDP growth and lower share of inventories.

What we can learn from this policy exercise is that a top-down innovation policy, if not coupled with alternative measures aimed at directly or indirectly tacking the roots of market concentration and/or compensating for the negative effects it produces on income distribution and aggregate demand, is likely to be ineffective in stimulating economic growth.

\subsection{Can concentration be good for the economy?}

The analysis carried out so far has shown that, in the absence of legal entry barriers, the initial wave of concentration is gradually re-absorbed due to the decline in technological discontinuities stemming from imitation activity, thus paving the

\footnotetext{
18 Note that, unless specified otherwise, in all policy experiments we keep active the engine of fiscal policy.

19 It must be stressed, however, that fiscal policy plays a crucial role in the baseline scenario as well independently from the labor market regime in place. To corroborate our results, we have replicated the policy experiment with no subsidy in the baseline scenario characterized by strong labor union $\left(\alpha_{w}=1\right)$. We find that the negative effects of a restrictive fiscal policy are much smaller in the baseline scenario compared to one characterized by weak labor union, both in term of output growth, unemployment rate and public deficit/GDP ratio. This means that the presence of a stronger unions, by supporting wage and aggregate demand, makes the economy more resilient to negative fiscal shock, in line with the findings of Caiani et al. (2019, 2020). Simulation results of the counter-factual fiscal policy experiment are available upon request.
} 

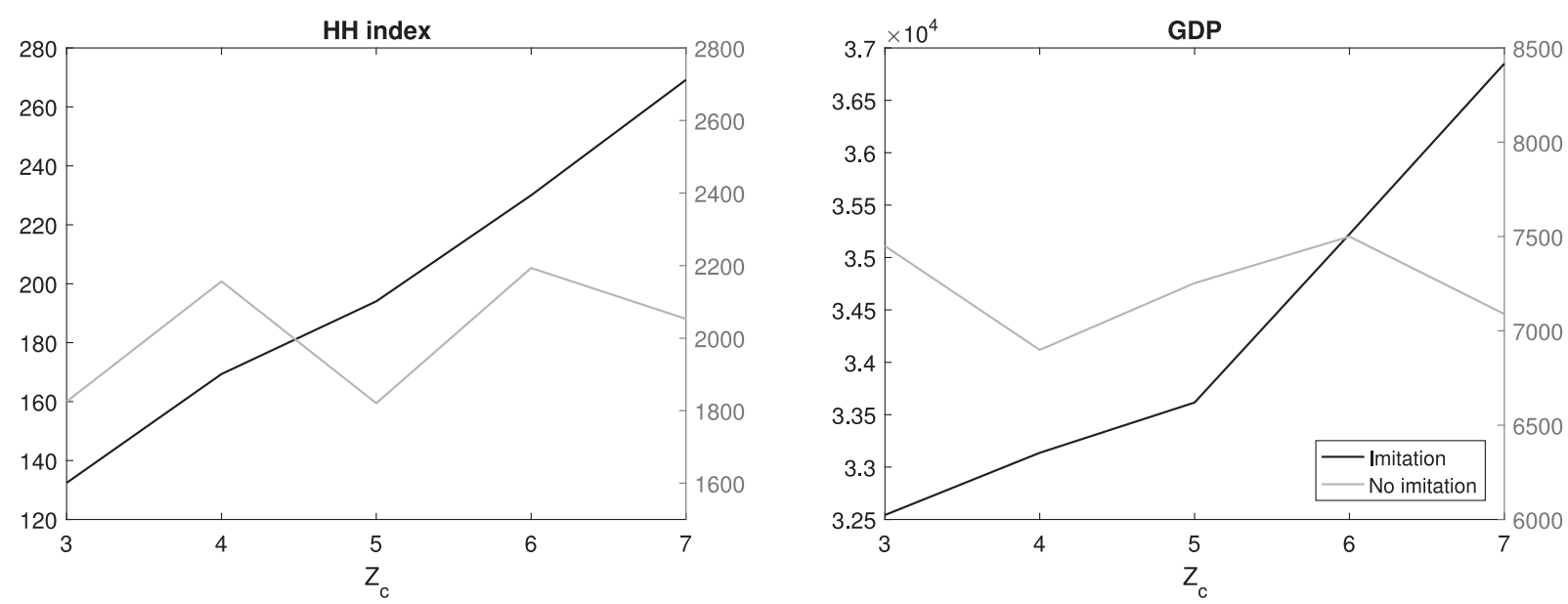

Fig. 10. Effects of a higher market competition, $Z_{c}$, on average HH index and GDP level under imitation and no-imitation scenario.

way for a competitive and self-sustained growth process. On the other hand, the presence of legal barriers to imitation is associated with a high and persistent market concentration, with long-lasting detrimental effects on income distribution and economic growth. The reason is twofold. On the demand side, greater profit margins resulting from the enhanced marker power cause a progressive shift in the income distribution from wages to profits, which, as long as profit earners have a lower propensity to consume than wage earners, leads to a reduction in aggregate consumption and demand. On the supply side, limited imitation activity in the K-sector, by curbing the diffusion of the best innovations among capital good firms, hampers technical change and productivity growth.

However, in the ongoing debate on the causes and consequences of rising concentration, some authors have stressed that a competition-driven concentration, by reallocating market shares towards more productive firms, may have a positive impact on output and productivity growth (Autor et al., 2017; 2020). Among the causes behind the increase in market competition, a special emphasis was given to the role of the improved search technologies in providing consumers with a greater availability of price comparisons on the internet (Akerman et al., 2021). According to this view, therefore, market concentration is considered to have efficiency-enhancing effects that eventually improve the economic performance.

The remaining part of this paper aims to investigate whether and under which conditions this hypothesis is verified in the framework of the present model. In particular, we want to explore, by means of a sensitivity analysis, the impact of an increase in the degree of competition, captured by parameter $Z_{c}$, i.e., the number of firms visited by consumers on the goods market, on concentration and aggregate production and how such a relationship is affected by entry barriers. The experiment is performed by running 25 Monte Carlo simulations for each value of $Z_{c}$ going from 3 (benchmark case) to 7; the mean values of HH index and GDP, averaged over time and across simulation runs, is then collected and displayed in Fig. 10. To assess the role of entry barriers, we replicate the experiment under the no-imitation scenario, i.e., $\chi=0$.

It can be seen that in the imitation scenario (black curve), a higher degree of competition leads to an increase in both concentration and total output. By contrast, in the presence of legal entry barriers (gray curve), as $Z_{c}$ increases, GDP slightly declines in spite of a (moderate) increase in the HH index. Therefore, it emerges that whereas in the imitation scenario a competition-driven concentration stimulates the economy, such efficiency-enhancing effects are canceled out by the presence of entry barriers. In fact, we have seen that when imitation is not allowed, the scarce diffusion of technological innovations allows large firms to consolidate their dominant position and thus exploit the market power generated by technological discontinuities. This interpretation is further corroborated by Fig. 11, which shows the evolution of the degree of variation in market shares, an index measuring the average number of ranks a firm moves up or down along the market share distribution in each period (Dawid et al., 2021). The higher the index, the more frequently firms change positions in the market, the stronger the business dynamism. We can see that in the no-imitation scenario the degree of variation in market shares is systematically lower and declining both over time (right panel) and by $Z_{c}$ (left panel). This means that the presence of legal entry barriers is associated not only with higher but also more persistent market concentration.

Considering the positive impact of an increase in competition-driven concentration on GDP in the absence of legal barriers, these findings suggest that it is the degree of persistence, more than the level per se, that determines whether or not market concentration benefits the economy. A high and volatile concentration may foster growth as long as competitive forces bring about a continuous reallocation of market shares towards more productive firms, without them having the opportunity to consolidate and exploit a dominant position. Conversely, a persistent market concentration triggered by the presence of legal barriers enables large firms to exert the enhanced market power to extract higher rents, with negative effects on income distribution and GDP. 

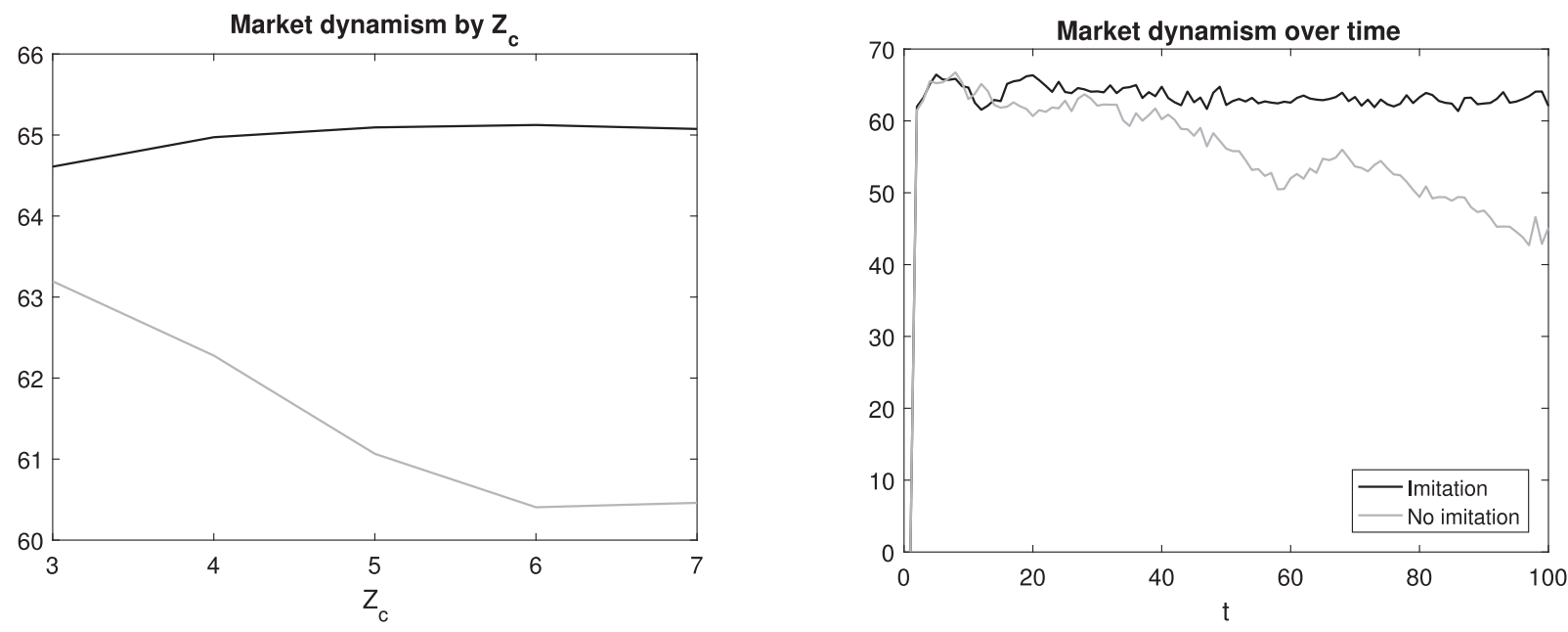

Fig. 11. The degree of persistence in market shares over time and by $Z_{c}$ under imitation and no-imitation scenario.

\section{Conclusion}

Building on the recent debate on rising concentration, stagnation and inequality (Stiglitz, 2019; Syverson, 2019; De Loecker et al., 2020), this paper aims at exploring the causes and consequences of rising market concentration, by focusing on the interplay of technical change and market power. We do this by developing a macro-evolutionary agent-based model with innovation dynamics in the capital good sector and knowledge accumulation in the consumption good sector. Kfirms perform innovation and imitation activities to improve the productivity embodied in the capital goods they produce by means of labor. C-firms produce a homogeneous consumption good by employing labor and heterogeneous capital and perform R\&D to accumulate technological knowledge. The choice of capital vintages by C-firms depends upon the "knowledge gap", i.e., the difference between the degree of capital good's technical advancement and the firm's level of technological knowledge.

Simulation results have shown that, in the short-run, the introduction of new innovations in the market generates a spontaneous wave of concentration in so far as firms with greater accumulated knowledge are able to exploit them, thus achieving productivity gains and larger market shares. Operating under oligopoly conditions, the emerging "superstar" firms seek to translate the enhanced market power intro higher mark-ups. As the weight of large firms grows over the economy, the increase in the weighted-average mark-up leads to a shift in the income distribution from wages to profits (Kalecki, 1942), which eventually undermines demand and growth (Keynes, 1936; Steindl, 1976). A stagnation tendency, thus, endogenously arises out of the normal functioning of an oligopoly economy characterized by knowledge-based technical entry barriers. Yet, the dynamics of industry concentration as well as its long-run economic effects is not straightforward. Indeed, further simulation experiments reveal that, whereas the first wave of concentration is triggered by technical entry barriers, which constrain firms' access to technological innovations, the evolution of concentration over time crucially depends on the presence (or lack thereof) of legal entry barriers, which affect the process of diffusion of technological innovations, thereby influencing the firms' ability to consolidate their position and exploit their market power.

From additional policy experiments, we find that labor market reforms aimed at weakening labor unions, by boosting profit margins and innovation, can foster a profit-led growth. Yet, the following slowdown in wages and demand has to be compensated by an anti-cyclical fiscal policy, in the absence of which the economy would remain stuck in a high unemployment-low growth trap. Moreover, while in the absence of entry barriers a reduction of transaction costs may promote a competition-driven concentration which benefits growth, innovation policies geared to spurring knowledge spillovers across firms risk to be ineffective as long as the technical ability to process them remains unequally distributed in a concentrated industry.

\section{Declaration of competing interest}

None.

\section{Acknowledgments}

This project has received funding from the European Union's Horizon 2020 research and innovation program under grant agreement No. 721846 (ExSIDE ITN). The authors would like to thank the two anonymous referees who provided insightful comments that helped improve the quality of the paper. Moreover, we are particularly grateful to Herbert Dawid, Domenico 
Delli Gatti, Cees Diks, Paul Levine, Tomasz Makarewicz, Tania Treibich and Federico Bassi for their support and advice. We are also thankful to the participants of CENDEF, CLE and IPKN seminars, BiGSEM colloquium, EAEPE 2020 and CEF 2021 conferences for providing useful comments. The usual disclaimer applies.

\section{Appendix A. Accounting and balance sheets}

In what follows we describe the agents' balance sheets and micro/macro accounting identities of the model.

The balance sheet for $\mathrm{C}$-firms respects the following accounting identity

$$
b_{i t}^{k} K_{i t}+D_{i t}+p_{i t} i n v_{i t}=L_{i t}+E_{i t},
$$

where $b_{i t}^{k} K_{i t}$ is the book value of capital, $D_{i t}$ is the firm's deposits, $p_{i t} i n v_{i t}$ is the inventories of C-goods valued at the current price, $L_{i t}$ is outstanding debt and $E_{i t}$ is equity, or net worth.

C-firms hold cash liquidity in forms of bank deposit, which evolves as follows:

$$
D_{i t}=D_{i t-1}+\pi_{i t}+\Delta L_{i t}-\theta L_{i t}-p_{j t} I_{i t}-d i v_{i t}-R D_{i t}
$$

where $\pi_{i t}$ is the firm's profits, $\theta L_{i t}$ the debt installments, $p_{j t} I_{i t}$ is the cost of new capital evaluated at current price of capital goods. $\operatorname{div}_{i t}$ is the dividend payments.

When the firm's equity turns negative or liquidity falls short of financial obligations, the firm is bankrupted and exits the market. Then, the owner uses his own wealth to recapitalize her.

For the sake of simplicity, K-firms do not borrow from the bank and employ only labor as input of production. Therefore, the balance sheet of K-firms reads

$$
D_{j t}=E_{j t},
$$

where their liquidity evolves as follows

$$
D_{j t}=D_{j t-1}+\pi_{j t}-d i v_{j t}
$$

Households' wealth $E_{h t}$ coincides with their deposit $D_{h t}$, which evolves by adding up their income and subtracting the consumption expenditure.

$$
\begin{aligned}
& E_{h t}=D_{h t}, \\
& D_{h t}=D_{h t-1}+Y_{h t}-C_{h t} .
\end{aligned}
$$

As far as the bank is concerned, her balance sheet is given by

$$
R_{t}^{b}+L_{t}=D_{t}+E_{t}^{b}
$$

where $R_{t}^{b}$ are the bank's reserves, $L_{t}$ are total loans provided to C-firms and the Government, $D_{t}$ are households' deposits and $E_{t}^{b}$ is the bank's net worth.

Bank's profits are the sum of interest payments of $N_{F}^{s}$ solvent borrowers, including the Government; there are no costs, since deposits are not remunerated:

$$
\pi_{t}^{b}=\sum_{s=1}^{N_{F}^{s}} r_{s t} L_{s t}+r B_{t-1} .
$$

The bank's equity is updated as follows:

$$
E_{b, t+1}=E_{b t}+\left(1-d i v_{b}\right) \pi_{b t}-B D_{t},
$$

where $d i v_{b}$ is the constant fraction of dividends paid by the bank to capitalists. $B D_{t}$ stands for bad debt, and is the total value of interest payments due by $N_{F}^{n}$ insolvent borrowers, i.e. $B D_{t}=\sum_{n=1}^{N_{F}^{n}} L_{n t}$.

The following set of equations illustrate the system of interrelated aggregate balance sheets:

$$
\begin{aligned}
& R^{b}=D^{H}+M^{I}+M^{J}+E^{B} \\
& M^{I}=D^{I}-L^{I} \\
& M^{J}=D^{J}-L^{J}
\end{aligned}
$$

where $M^{I}=E^{I}-(K+\Delta)$ and $M^{J}=E^{J}-\Delta^{J}$ are money in the hands of, respectively, C-firms and K-firms.

\section{Appendix B. Parameter setting}


Table B.1

Benchmark parameter setting.

\begin{tabular}{|c|c|c|}
\hline Symbol & Description & Value \\
\hline$W$ & Number of workers & 2000 \\
\hline$F$ & Number of C-firms & 200 \\
\hline$N$ & Number of K-firms & 20 \\
\hline$Z_{c}$ & Number of C-firms visited by consumer & 3 \\
\hline$Z_{u}$ & Number of firms visited by unemployed workers & 5 \\
\hline$Z_{\text {imi }}$ & Number of K-firms visited by imitators & 4 \\
\hline $\bar{l}$ & Capital-labor ratio & 2 \\
\hline$\alpha_{w}$ & Wage-productivity elasticity & 1 \\
\hline $\bar{\omega}$ & Desired utilization rate & 0.85 \\
\hline$\kappa$ & Desired inventories rate & 0.1 \\
\hline$\rho$ & Sales adaptive expectation parameter & 0.25 \\
\hline$\left\{c_{y}^{w}, c_{y}^{k}\right\}$ & Marginal propensity to consume out of income & $\{0.90,0.60\}$ \\
\hline$c_{f}$ & Marginal propensity to consume out of wealth & 0.05 \\
\hline$v$ & Unemployment subsidy rate & 0.40 \\
\hline$\left\{\tau^{w}, \tau^{k}\right\}$ & Tax rate on labor and capital income & $\{0.04,0.02\}$ \\
\hline div & Firms-bank payout ratio & 0.20 \\
\hline$\delta$ & Depreciation rate of capital & 0.03 \\
\hline$\delta^{\operatorname{in} v}$ & Depreciation rate of inventories & 0.30 \\
\hline$\delta^{z}$ & Depreciation rate of knowledge & 0.005 \\
\hline$\sigma^{c, k}$ & R\&D effort & 0.30 \\
\hline$\chi$ & R\&D allocation between innovation-imitation & 0.50 \\
\hline$\zeta$ & Search capabilites parameter & 0.30 \\
\hline$\eta$ & Absorptive capacity parameter & 0.03 \\
\hline$\psi$ & Degree of knowledge spillovers & 0.1 \\
\hline$\beta$ & Intensity of choice of K-good & 15 \\
\hline$\lambda$ & Intensity of choice of C-good & 1 \\
\hline$s$ & Unemployment subsidy rate & 0.4 \\
\hline$r$ & Risk-free rate & 0.003 \\
\hline$\theta$ & Rate of debt reimbursement & 0.05 \\
\hline$\mu_{b}$ & Bank gross mark-up & 1.2 \\
\hline$\phi$ & Bank loss parameter & 1.2 \\
\hline$A_{0}$ & Initial value of $\mathrm{C}$-firms productivity & $1 / 3$ \\
\hline$B_{0}$ & Initial value of K-firms productivity & $1 / 2$ \\
\hline$\left\{a_{1}, a_{2}\right\}$ & Effective productivity parameters & $\{3,1.5\}$ \\
\hline$\left(\mu_{F N_{1}}, \sigma_{F N_{1}}^{2}\right)$ & Folded Normal Distribution parameters for product innovation & $(0.03,0.008)$ \\
\hline$\left(\mu_{\mathrm{FN}_{2}}, \sigma_{\mathrm{FN}_{2}}^{2}\right)$ & Folded Normal Distribution parameters for process innovation & $(0.02,0.008)$ \\
\hline$\left(\mu_{\mathrm{FN}_{3}}, \sigma^{2}{ }_{\mathrm{FN}_{3}}\right)$ & Folded Normal Distribution parameters for mark-up & $(0.02,0.008)$ \\
\hline
\end{tabular}

\section{References}

Acemoglu, D., Zilibotti, F., 2001. Productivity differences. Q. J. Econ. 116 (2), 563-606.

Aistleitner, M., Gräbner, C., Hornykewycz, A., 2020. Theory and Empirics of Capability Accumulation: Implications for Macroeconomic Modelling. Technical Report. ICAE Working Paper Series.

Akerman, A., Leuven, E., Mogstad, M., 2021. Information frictions, internet and the relationship between distance and trade. Am. Econ. J.. Forthcoming

Alvarez, L.J., Dhyne, E., Hoeberichts, M., Kwapil, C., Le Bihan, H., Lünnemann, P., Martins, F., Sabbatini, R., Stahl, H., Vermeulen, P., et al., 2006. Sticky prices in the euro area: a summary of new micro-evidence. J. Eur. Econ. Assoc. 4 (2-3), 575-584.

Assenza, T., Delli Gatti, D., Grazzini, J., 2015. Emergent dynamics of a macroeconomic agent based model with capital and credit. J. Econ. Dyn. Control 50, $5-28$.

Atkinson, A.B., 2015. Inequality: What Can Be Done?. Harvard University Press, Cambridge, MA.

Autor, D., Dorn, D., Katz, L.F., Patterson, C., Van Reenen, J., 2017. Concentrating on the fall of the labor share. Am. Econ. Rev. 107 (5), $180-185$.

Autor, D., Dorn, D., Katz, L.F., Patterson, C., Van Reenen, J., 2020. The fall of the labor share and the rise of superstar firms. Q. J. Econ. 135 (2), 645-709.

Baran, P.A., Sweezy, P.M., 1966. Monopoly Capital: An Essay on the American Economic and Social Order. Monthly Review Press, New York.

Barkai, S., 2020. Declining labor and capital shares. J. Finance. 75 (5), 2421-2463.

Benmelech, E., Bergman, N., Kim, H., 2018. Strong Employers and Weak Employees: How Does Employer Concentration Affect Wages? Technical Report. National Bureau of Economic Research.

Bresnahan, T.F., Brynjolfsson, E., Hitt, L.M., 2002. Information technology, workplace organization, and the demand for skilled labor: firm-level evidence. Q. J. Econ. 117 (1), 339-376.

Brynjolfsson, E., Hitt, L.M., 2000. Beyond computation: information technology, organizational transformation and business performance. J. Econ. Perspect. $14(4), 23-48$.

Caiani, A., 2017. Innovation dynamics and industry structure under different technological spaces. Italian Econ. J. 3 (3), 307-341.

Caiani, A., Catullo, E., Gallegati, M., 2018. The effects of fiscal targets in a monetary union: a multi-country agent-based stock flow consistent model. Ind. Corp. Change 27 (6), 1123-1154.

Caiani, A., Russo, A., Gallegati, M., 2019. Does inequality hamper innovation and growth? An AB-SFC analysis. J. Evol. Econ. 29 (1), 177-228.

Caiani, A., Russo, A., Gallegati, M., 2020. Are higher wages good for business? An assessment under alternative innovation and investment scenarios. Macroecon. Dyn. 24 (1), 191-230.

Cantner, U., Pyka, A., 1998. Absorbing technological spillovers: simulations in an evolutionary framework. Ind. Corp. Change 7 (2), $369-397$.

Cardaci, A., 2018. Inequality, household debt and financial instability: an agent-based perspective. J. Econ. Behav. Organ. 149, 434-458.

Cohen, W.M., Levinthal, D.A., 1989. Innovation and learning: the two faces of R\&D. Econ. J. 99 (397), 569-596.

Cohen, W.M., Levinthal, D.A., 1990. Absorptive capacity: a new perspective on learning and innovation. Adm Sci. Q. 128-152.

Crouzet, N., Eberly, J.C., 2019. Understanding Weak Capital Investment: The Role of Market Concentration and Intangibles. Technical Report. National Bureau of Economic Research. 
Dawid, H., 2006. Agent-based models of innovation and technological change. Handb. Comput. Econ. 2, 1235-1272.

Dawid, H., Delli Gatti, D., 2018. Agent-based macroeconomics. In: Handbook of Computational Economics, vol. 4. Elsevier, North Holland, pp. 63-156.

Dawid, H., Harting, P., van der Hoog, S., Neugart, M., 2019. Macroeconomics with heterogeneous agent models: fostering transparency, reproducibility and replication. J. Evol. Econ. 29 (1), 467-538.

Dawid, H., Harting, P., Neugart, M., 2018. Cohesion policy and inequality dynamics: insights from a heterogeneous agents macroeconomic model. J. Econ. Behav. Organ. 150, 220-255.

Dawid, H., Harting, P., Neugart, M., 2021. The role of (de-) centralized wage setting for industry dynamics and economic growth: an agent-based analysis with the eurace@ unibi model. In: Dynamic Analysis in Complex Economic Environments. Springer, pp. 205-230.

De Loecker, J., Eeckhout, J., Unger, G., 2020. The rise of market power and the macroeconomic implications. Q. J. Econ. 135 (2), $561-644$.

Decker, R.A., Haltiwanger, J., Jarmin, R.S., Miranda, J., 2016. Declining business dynamism: what we know and the way forward. Am. Econ. Rev. 106 (5), 203-207.

Deissenberg, C., Van Der Hoog, S., Dawid, H., 2008. EURACE: a massively parallel agent-based model of the european economy. Appl. Math. Comput. 204 (2), 541-552.

Delli Gatti, D., Fagiolo, G., Gallegati, M., Richiardi, M., Russo, A., 2018. Agent-Based Models in Economics: A Toolkit. Cambridge University Press, Cambridge, MA.

Delli Gatti, D., Gallegati, M., Greenwald, B., Russo, A., Stiglitz, J.E., 2010. The financial accelerator in an evolving credit network. J. Econ. Dyn. Control 34 (9), 1627-1650.

Di Bucchianico, S., 2020. Discussing secular stagnation: a case for freeing good ideas from theoretical constraints? Struct. Change Econ. Dyn. 55, $288-297$.

Doms, M., Dunne, T., Troske, K.R., 1997. Workers, wages, and technology. Q. J. Econ. 112 (1), 253-290.

Dosi, G., 1982. Technological paradigms and technological trajectories: a suggested interpretation of the determinants and directions of technical change. Res. Policy 11 (3), 147-162.

Dosi, G., Fagiolo, G., Napoletano, M., Roventini, A., 2013. Income distribution, credit and fiscal policies in an agent-based Keynesian model. J. Econ. Dyn. Control 37 (8), 1598-1625.

Dosi, G., Fagiolo, G., Roventini, A., 2010. Schumpeter meeting Keynes: a policy-friendly model of endogenous growth and business cycles. J. Econ. Dyn. Control 34 (9), 1748-1767.

Dosi, G., Guarascio, D., Ricci, A., Virgillito, M.E., 2019. Neodualism in the italian business firms: training, organizational capabilities, and productivity distributions. Small Bus. Econ. 1-23.

Dosi, G., Lechevalier, S., Secchi, A., 2010. Introduction: interfirm heterogeneitynature, sources and consequences for industrial dynamics. Ind. Corp. Change 19 (6), 1867-1890.

Dosi, G., Nelson, R.R., 2010. Technical change and industrial dynamics as evolutionary processes. In: Handbook of the Economics of Innovation, vol. 1. Elsevier, North Holland, pp. 51-127.

Dosi, G., Pereira, M.C., Roventini, A., Virgillito, M.E., 2018. The effects of labour market reforms upon unemployment and income inequalities: an agent-based model. Socioecon. Rev. 16 (4), 687-720.

Dosi, G., Pereira, M.C., Virgillito, M.E., 2017. The footprint of evolutionary processes of learning and selection upon the statistical properties of industrial dynamics. Ind. Corp. Change 26 (2), 187-210.

Dosi, G., Roventini, A., 2019. More is different... and complex! The case for agent-based macroeconomics. J. Evol. Econ. 29 (1), 1-37.

Dynan, K.E., Skinner, J., Zeldes, S.P., 2004. Do the rich save more? J. Polit. Economy 112 (2), 397-444.

Fabiani, S., Druant, M., Hernando, I., Kwapil, C., Landau, B., Loupias, C., Martins, F., Mathä, T., Sabbatini, R., Stahl, H., Stokman, A., 2005. The Pricing Behaviour of Firms in the Euro Area: New Survey Evidence. NBB working paper nr. 76, November 2005.

Fagiolo, G., Roventini, A., 2017. Macroeconomic policy in DSGE and agent-based models redux: new developments and challenges ahead. J. Artif. Soc. Social Simul. $20(1)$.

Giovannoni, O.G., 2014. What Do We Know About the Labor Share and the Profit Share? Part III: Measures and Structural Factors. Working Paper 805. Levy Economics Institute.

Giri, F., Riccetti, L., Russo, A., Gallegati, M., 2019. Monetary policy and large crises in a financial accelerator agent-based model. J. Econ. Behav. Organ. 157, 42-58.

Grullon, G., Larkin, Y., Michaely, R., 2019. Are US industries becoming more concentrated? Rev. Financ 23 (4), 697-743.

Gutiérrez, G., Philippon, T., 2016. Investment-Less Growth: An Empirical Investigation. Technical Report 22897. National Bureau of Economic Research.

Gutiérrez, G., Philippon, T., 2017. Declining Competition and Investment in the US. Technical Report 23583. National Bureau of Economic Research.

Gutiérrez, G., Philippon, T., 2019. The Failure of Free Entry. Technical Report 26001. National Bureau of Economic Research.

Hepp, J., 2021. Being Small at the Right Moment: Path Dependence after a Shift in the Technological Regime. Bielefeld Working Papers in Economics and Management.

Kalecki, M., 1942. A theory of profits. Econ. J. 52 (206/207), 258-267.

Karabarbounis, L., Neiman, B., 2014. The global decline of the labor share. Q. J. Econ. 129 (1), 61-103.

Keynes, J.M., 1936. The General Theory of Employment, Interest and Money. Kessinger Publishing.

Krugman, P., 2014. Four Observations on Secular Stagnation. CEPR Press London, pp. 61-68.

Levin, R.C., Klevorick, A.K., Nelson, R.R., Winter, S.G., Gilbert, R., Griliches, Z., 1987. Appropriating the returns from industrial research and development. Brookings Pap. Econ. Act. 1987 (3), 783-831.

Mairesse, J., Greenan, N., Topiol-Bensaid, A., 2001. Information Technology and Research and Development Impacts on Productivity and Skills: Looking for Correlations on French Firm-Level Data. Working Paper 8075. National Bureau of Economic Research.

Malerba, F., Orsenigo, L., 1996. Schumpeterian patterns of innovation are technology-specific. Res. Policy 25 (3), 451-478.

Nelson, R., Winter, S., 1982. An Evolutionary Theory of Economic Change. Cambridge, Massachusetts, and London, England.

Nelson, R.R., Winter, S.G., 1978. Forces generating and limiting concentration under Schumpeterian competition. Bell J. Econ. 524-548.

Orhangazi, Ö., 2019. The role of intangible assets in explaining the investment-profit puzzle. Cambridge J. Econ. 43 (5), $1251-1286$.

Piketty, T., 2014. Capital in the Twenty-First Century. Harvard University Press, Cambridge, MA.

Riccetti, L., Russo, A., Gallegati, M., 2015. An agent based decentralized matching macroeconomic model. J. Econ. Interact. Coord. 10 (2), 305-332.

Russo, A., Riccetti, L., Gallegati, M., 2016. Increasing inequality, consumer credit and financial fragility in an agent based macroeconomic model. J. Evol. Econ. 26 (1), 25-47.

Steindl, J., 1976. Maturity and Stagnation in American Capitalism, vol. 4. NYU Press.

Stiglitz, J., 2019. People, Power, and Profits: Progressive Capitalism for an Age of Discontent. Penguin UK.

Stiglitz, J.E., 2012. The Price of Inequality: How Today's Divided Society Endangers our Future. WW Norton \& Company.

Stock, J.H., Watson, M.W., 1999. Business cycle fluctuations in US macroeconomic time series. Handb. Macroecon. 1, 3-64.

Stockhammer, E., 2005. Shareholder value orientation and the investment-profit puzzle. J. Post Keynes Econ. 28 (2), $193-215$.

Summers, L.H., 2014. US economic prospects: secular stagnation, hysteresis, and the zero lower bound. Bus. Econ. 49 (2), $65-73$.

Sylos Labini, P., 1967. Oligopolio e Progresso Tecnico. Einaudi, Torino.

Syverson, C., 2019. Macroeconomics and market power: context, implications, and open questions. J. Econ. Perspect. 33 (3), $23-43$.

Turco, E.M., 2018. Are stock buybacks crowding out real investment? Empirical evidence from US firms. Dissertation, University of Amsterdam, Amsterdam Ph.D. thesis.

Van Treeck, T., 2014. Did inequality cause the us financial crisis? J. Econ. Surv. 28 (3), 421-448.

Villani, D., 2021. The rise of corporate net lending among G7 countries: a firm-level analysis. Rev. Polit. Economy 1-24. 